\title{
LA CIUDAD DE ARCÁVICA Y LA FUNDACIÓN DEL MONASTERIO SERVITANO*
}

\author{
POR
}

Rafael Barroso Cabrera y Jorge Morin de Pablos

\section{RESUMEN}

La ciudad de Arcávica fue durante el periodo visigodo uno de los tres obispados situados en la actual provincia de Cuenca junto a los de Segóbriga y Valeria. No aparece mencionada en las fuentes de forma directa, a excepción de las firmas de sus prelados en las actas conciliares. Aún así, evidencian la importancia de este yacimiento los numerosos restos arqueológicos localizados en torno al cerro que albergo la ciudad celtíbero-romana de Ercávica. No obstante, el in terés de su estudio se centra sobre todo en el problema de la localización del monasterio Servitano fundado por el norteafricano Donato y sus setenta monjes. Su ubicación en tierras arcavicenses se presenta fundamental para la comprensión de la arqueología del yacimiento y de buena parte de la historia de España durante los cruciales años en que transcurren los reinados de Leovigildo y su hijo Recaredo.

\section{Arstract}

The city of Arcavica and the Foundation of the Servitanus Monastery

During the Visigothic period, the city of Arcavica was one of the three bishoprics placed in the present province of Cuenca, together with those of Segobriga and Valeria. With the exception of the signatures of Arcavica's prelates on Council minutes there is no direct mention of the city in the sources available. Even so, the importance of its archaeological site is reflected in the numerous remains found on the hill where the Roman-Celtiberian city of Ercavica used to lay. 
However important the city itself may be, archaeological research in this area is mainly focused on the problem of locating the Servitanus Monastery founded by the North-African abbot Donatus and his seventy monks. lis location in Arcavica, as the authors of the present article defend, is essential to interpret the remains found in this site and to understand a significant part of Spain's history that takes place during the crucial years of Leovigild's and Recared's reigns.

Ha transcurrido mucho tiempo desde los días en que Fray Prudencio de Sandoval (1553-1620), en su Primera Parte de las Fundaciones de San Benito, hacía benedictinos a la totalidad de los monasterios visigodos famosos. Entre ellos se encontraba el monasterio Servitano. A pesar de que este origen benedictino haya quedado descartado por completo en la actualidad, no es éste el único problema que plantea la fundación del abad Donato. Entre ellos sigue en pie, de forma destacada, la polémica acerca de su localización concreta.

El presente artículo pretende arrojar algo de luz sobre este asunto, así como sobre los personajes vinculados a la historia del monasterio. Con este fin nos hemos propuesto realizar una nueva lectura de los testimonios literarios a través de los datos proporcionados por la investigación arqueológica ${ }^{1}$.

\section{LOCALIZACIÓN}

El yacimiento romano de Ercávica (Cañaveruelas, Cuenca) se encuentra situado en el Castro de Santaver, en la Alcarria conquense, muy cerca de la raya con la provincia de Guadalajara. Aparece citado con cierta asiduidad en las fuentes visigodas con motivo de la asistencia de sus obispos a los Concilios toledanos, hecho registrado al menos desde el III Concilio de Toledo, celebrado en el año $589^{2}$.

* Un resumen del presente artículo fue presentado al $1^{\circ}$ Congresso de Arqueologia Peninsular celebrado en Oporto, en Octubre de 1994, y está publicado en la revișta portuguesa Trabalhos de Antropologia e Einologia, vol.34 (3-4), Porto, 1994, p.287-306.

Quisiéramos expresar desde aquí nuestro agradecimiento al profesor A. ARBEITER, del instituto Arqueológico Alemán de Madrid por sus acertados comentarios al texto original. Asimismo, a SANTIAGo PAlomero, del Museo Sefardi de Toledo, y a YaSMINA Álvarez por sus indicaciones acerca del yacimiento y las diversas campañas de excavación; a AMPARO MARTíN ESPINOSA, ALMUDENA SALVADOR y SONIA y ANDRES JAQUE OVEJERO que colaboraton activamente en las últimas campañas arqueológicas, aportando interesantes ideas. Igualmente, a D. JESÚs MORIN ALBA y MARIANO LOPEZ ALONSO por su inestimable colaboración en la realización de la planimetría.

${ }^{2}$ Sobre los obispos asistentes véase: H. FLOREZ, España Sagrada. Theatro geográficohistórico de las Iglesias de España, t. VII. Madrid, 1782. De la iglesia Arcavicense o Ercavicense, p.72-79 (desde ahora ES) y L. A. GARClA MORENO, Prosopografia del Reino visigodo de Toledo. Salamanca, 1974, n²96-302, p.131-133.

De Hispania Visigoda

Hispania Sacra 48 (1996) 
Ya el Padre Flórez advirtió la variedad de denominaciones con que aparece citada esta sede en los distintos autores y manuscritos conservados: iglesia arcavicense, archavicense, arravicense, arcaudense, ircavicense, etc. ${ }^{3} \mathrm{Si}-$ guiendo el criterio marcado por los manuscritos de la época y por los distintos autores que se han ocupado del tema, hemos preferido utilizar la denominación de Arcávica para la ciudad medieval y la de Ercávica para referimos a la ciudad celtibérica y romana.

Durante mucho tiempo se llegó a especular largamente sobre la ubicación exacta de la ciudad de Arcávica, debido al problema que planteó en su día la localización de Segóbriga y su correspondiente obispado, problema complicado además por el interés del episcopado y la corte toledanos de extender su jurisdicción sobre tierras levantinas. La localización de los antiguos obispados conquenses se vió enmarañada aún más por las discusiones entre los eruditos castellanos y levantinos, disputa teñida muchas veces de un exceso e insano celo localista ${ }^{4}$.

Desde Ambrosio de Morales se viene aceptando que la antigua ciudad de Arcávica estaba ubicada en Peñaescrita o en Santaver (despoblado situado en el término municipal de Cañaveruelas), desechando la localización comúnmente aceptada de Arcas (Cuenca) o Arcos de Jalón (Soria), ambas basadas en falsas etimologías ${ }^{5}$. La localización de Arcávica en el Castro de Santaver aparece recogida también en el padre Flórez, y se veía apoyada además en la Pseudo Hitación de Wamba (una relación de sedes episcopales atribuida a este rey visigodo, pero en realidad datada a comienzos del siglo XII) y por la reunión de esta sede y la valeriense en la de Cuenca después de la reconquista de la ciudad por Alfonso VIII en $1177^{6}$. Idéntica opinión fue compartida posteriormente por otros distinguidos autores que trataron el problema, entre los

${ }^{3}$ ES, VII, p.53-56; M. LÓPEZ, Memorias históricas de Curenca y su obispado. Biblioteca Conquense V, vol.I, Madrid, 1949 (1a ed. 1787) p.122-123. La confusión de $E$ por $A$ es frecuente en los escritos visigodos: J. MUÑoz RIVero, Paleografía visigoda. Madrid, 1919, p.113.

${ }^{4}$ La mayoría de los autores que se han ocupado de las sedes episcopales conquenses de época visigoda lo han hecho guiados por la idea de solucionas el problema de su precisa localización. No nos extenderemos sobre este particular porque ya to hicieron en magistrales trabajos D. Pfo BELTRÁN VillagraSA, "Segóbriga" ArchPrehistLev 4 (1953) p.23l-253 y D. MarTín ALmagro BaSCH, Segobriga I. Los textos de la Antiguiedad, EAE 122 (1983) p.33-176 y Segobriga IL. Inscripciones ibéricas, latinas paganas y latinas cristianas. EAE 128 (1984) p.391-419.

5 A. DE MORALES, Las antigüedades de las ciudades de España que van nombradar en la Corónica... Madrid, 1792, p.89ss.

${ }^{6} \mathrm{ES}, \mathrm{VII}, \mathrm{p} .56-64$. 
que cabe destacar a D. José Cornide y al erudito padre Fidel Fita, ya en el siglo pasado?.

En primer lugar, es interesante remarcar la noticia que consigna el padre Flórez, entre otros autores, de la cercanía de Arcávica a la ciudad de Recópolis, fundación hecha por Leovigildo para servir de sede regia a su hijo Recaredo. Según este autor, Recópolis se hallaba no lejos de nuestra ciudad, distando "poco más de dos leguas de Ercavica a la orilla del Tajo entre Sasamón y Zurita $^{\prime \prime}$. Efectivamente, su localización en el Cerro de la Oliva (Zorita de los Canes, Guadalajara) no dista mucho de nuestro yacimiento. De hecho, se ha señalado la utilización de materiales constructivos de la Ercávica romana en la recién creada urbe visigoda ${ }^{9}$. La construcción del pantano de Buendía, no obstante, supone que la comunicación entre ambos yacimientos sea actualmente más complicada que la que tuvieron en la antigüedad, donde un camino enlazaba ambas ciudades con la vía que se dirigía hacia Segontia (Sigüenza) y Caesaraugusta (Zaragoza) ${ }^{10}$.

La relación entre Recópolis y otras ciudades del entorno alcarreño está bien atestiguada por la arqueología. Así lo demuestra, por ejemplo, el hallazgo de un pendiente y un anillo de oro y gemas en la cercana Huete, así como de una pareja de zarcillos de tipo cestilla fabricados en oro y granates procedente de Albendea, en la misma provincia de Cuenca. Las piezas de Huete interesan además porque fueron realizadas en algún taller aúlico, casi con seguridad, dada la similitud técnica y decorativa, en el mismo donde se fabricaron las famosas coronas de Guarrazar (Toledo). Las joyas de Albendea, por su parte,

\footnotetext{
${ }^{7}$ J. CORNIDE, "Noticia de las antiguedades de Cabeza de Griego." MAcHist III (1799) p.83-86; F. FITA, "Sebastián, Obispo de Arcávica y de Orense. Su Crónica y la del Rey Alfonso IIl." BAcHist XLI (1902) p.324-332.

${ }^{8}$ ES, Vl, p.414 y t.VII, p.7I. Sobre Recópolis, véanse los trabajos de K. RaDDatz, "Studien zu Reccopolis. (i) Die archäologischen Befunde." MM 5 (1964) p.213-233; D. Claude, "Studien zu Reccopolis. (2) Die historische Situation." MM 6 (1965) p.167-194; L. VAZquEZ DE PARGA, "Studien zu Recopolis. (3)." MM 8 (1967) p.259-280; L. OLMO ENCISO, ha dedicado numerosos artículos a este yacimiento, entre otros La ciudad de Recópolis y el hábitat en la zona central de la península ibérica durante la época visigoda, en Homenaje al profesor M. Almagro, t.IV, Madrid, 1983, p.71-72 y La ciudad visigoda de Recópolis. I CongHistCM. t.IV. Toledo, 1988, p.305-311. Un resumen global puede verse en el interesante artículo de F. Fernández Izquierdo, "Aportación al estudio de Recópolis." ArchEspA 55 (1982) p.119-136.

9 L. VÁZQueZ DE PARGA, "Studien zu Recopolis", p.275; F. FERnÁndeZ IZQuierdo, "Aportación al estudio", p.135.

${ }^{10} \mathrm{~J}$. M. ABASCAL PALAZÓN, Vías de comunicación romanas en la provincia de Guadalajara. Guadalajara, 1982, p.89; S. PALOMERo PlAZA, Las vias romanas de la provincia de Cuenca. Cuenca, 1987 , p.53ss.
} 
parecen ser un trabajo de imitación, algo más sencillo en cuanto a su realización, si bien de un valor artístico y crematístico nada desdeñable ${ }^{11}$.

El presente trabajo no pretende, en modo alguno, dar a conocer nuevos datos arqueológicos de las excavaciones realizadas durante los últimos años en el yacimiento de Arcávica, datos que en la actualidad son objeto de estudio para una tesis doctoral por parte de D. Carlos Moncó García ${ }^{12}$, sino tan sólo incidir en ciertos aspectos ya conocidos de este yacimiento y reinterpretarlos de nuevo según el testimonio de las fuentes escritas ${ }^{13}$.

\section{ARCÁVICA EN LAS FUENTES VISIGODAS}

Las fuentes literarias de la época constituyen uno de los elementos fundamentales para el estudio del pasado de Arcávica. No son, sin embargo, frecuentes las alusiones directas a la ciudad, excepto, como ya se ha señalado, en lo referente a los obispos signatarios de las actas conciliares posteriores al año $589^{14}$.

La primera cuestión que suscita la lectura de las fuentes sinodales es una referencia vaga a la existencia de una región celtibérica, individualizada frente a otra que denominan carpetana. La mención más antigua a esta pro-

" R. Barroso Cabrera, "Dos piezas de orfebreria hispanovisigoda procedentes de Huete (Cuenca) en el M.A.N." BMusMadr VIll $n^{\circ} 1-2$. (1990) p.83-90.

${ }_{12}$ Nuestra discrepancia con algunas de las ideas mantenidas por D. CARLOS MONCó no va en demérito de la intensa labor realizada por éste durante tantos años, más aún ante las duras condiciones en que ha tenido que desarrollar su trabajo muchas veces. Renimente, es de justicia reconocer que lo que, hoy por hoy, podemos saber acerca de la Ercávica medieval es, en gran medida, gracias a su esfuerzo y dedicación.

${ }_{13}$ M. Osuna RuIz, "Las relaciones judeo-cristianas en la provincia de Cuenca, desde la época romana a los siglos XII-XIII, a la luz de los últimos descubrimientos arqueológicos." Estárhebr XXV fasc.2 (1976) p.151-154 y "Excavaciones arqueologicas en Erḉvica. Castro de Santaver, Cañaveruelas (Cuenca). Agosto, 1973." NAH 5 (1977) p.25-28; C. MonCO GARCía, El eremitorio y la necrópolis hispano visigoda de Ercávica. I CAME, Huesca, 1985 (Zaragoza, 1986) t.II, p.241-257; "El eremitorio de la necrópolis alto-medieval de Ercávica. Cañaveruelas. Cuenca." CentEstPl 6 (1986) y C. MONCÓ GARCÍA y A. JIMÉNEZ PÉREZ, Las estelas discoideas de la necrópolis del Ejido-Santaver y de la iglesia de San Pedro de Huete. Cuenca. III CAME, Oviedo, 1989 (Oviedo, 1992) p.534-543; Y. Álvarez Delgado, Cerámicas comunes con y sin decoración, siglo IX. Atcávica (Cuenca). II CAME, Madrid, 1987, p.400-412 y "Cerámicas del siglo IX de Arcávica (Cuenca)", BolArqMed 3 (1989) p.109-121. Sobre la historia de la ciudad son más abundantes los estudios, centrándose sobre todo en la polémica sobre la ubicación de los obispados; por ello nos remitimos a los trabajos de P. BELTRÁN y $M$. ALMAGRo Basch citados en la nota 4. Queremos resaltar, sin embargo, un ensayo divulgativo, pero muy acertado, de D. FloRenCio MARTínez Rulz, "El Monasterio Servitano, en Ercávica", publicado en El Dia de Cuenca, Domingo 13-l-1991, p. 10-1 l.

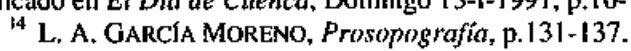


vincia Celtiberia es la epístola del obispo Montano de Toledo a Toribio de Astorga, donde se señala ya la diferencia entre los dos territorios, perceptible al menos entre los contemporáneos:

"... quod tamen privilegium decessori nostro necnon dominis et fratribus nostris Carpetania et Celtiberiae episcopis vester coepiscopus fecit,..." ${ }^{15}$.

Aparte de la referida diferencia entre ambas, del documento puede colegirse que las dos regiones estaban bajo la jurisdicción de Toledo. En el mismo contexto hay que incluir las referencias explícitas a tal situación hechas por los obispos de Toledo y Arcávica en las actas del III Concilio de Toledo:

"Eufimius in Christi nomine ecclesiae catholicae Toletanae metropolitanus episcopus provinciae Carpetaniae..." ${ }^{16}$; "Petrus <Ircavicensis> Celtiferiae episcopus..." 17 .

Con posterioridad a estos acontecimientos, el escritor franco Gregorio de Tours menciona la existencia de plagas de langosta en la provincia Carpeta$\mathrm{na}^{18}$. En realidad, y como han puesto de manifiesto Carmen Codoñer ${ }^{19}$ y Abilio Barbero ${ }^{20}$, la existencia de estas dos nuevas entidades territoriales, que distorsionan la división administrativa heredada del poder imperial, sería una consecuencia de la realidad política del momento: se trata, ante todo, de una división forzada por el hecho de que la capital de la Cartaginense (es decir, la sede metropolitana) está en manos de los bizantinos ${ }^{21}$. En cualquier caso, hay que subrayar la subordinación de la Celtiberia a la Carpetania, o, más exactamente, a la sede metropolitana de esta última. Se trata, pues, de una situación de eventualidad que no será solventada definitivamente hasta la celebración del Sínodo de Gundemaro del año 610 en el que se reconoce el estatuto de

${ }^{15}$ F. DE LORENZANA, SS. PP. Toletanorum quotquot extant opera... tomus primus, etc. Matritj MDCCLXXXII. Monumenta Toletana Sacra, Toleti, 1972, p.10-1 1; J. Vives Gatell, Concilios visigóticos e hispano-romanos. España cristiana, vol.I, Barcelona-Madìd, 1963, p.50-5I.

${ }^{16}$ Ibidem, p. 136.

${ }^{17}$ Jbidem, p.137; ES, VII, p.56-57.

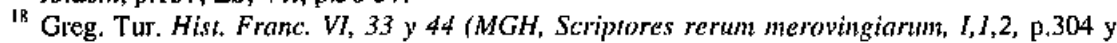
316). Sobre este problema se ocupó en extenso M. Barcelo, "Les plagues de llagost a la Carpetània, 578-649." Esthistagr l (1978) p.67-84.

19 C. CODOÑER MERINO, El "De viris IIIustribus" de Ildefonso de Toledo. Estudio y edición crítica. Universidad de Salamnnca, 1972, p.62-64 (desde ahora, Ildefonso de Toledo).

${ }^{20}$ A. BARBERO DE AGULERA, "Las divisiones eclesiásticas y las relaciones entre la Iglesia y el Estado en la España de los siglos VI-VII." ActSalmant (1989) p.185-187.

${ }^{21}$ C. CODONER MERINo, Ildefonso de Toledo, p.58-64. Sobre este mismo tema: A. Barbero de AGulLERA, "Las divisiones", p. 174-177. Este ưltimo autor insiste en sítuar erróneamente Arcávica en Cabeza de Griego. En realidad, este sitio corresponde a Segobriga, caput Celtiberiae (Plinio, NH, lII, 25), en oposición a Clunia, Celtiberiae finis (NH, Ill, 27): L. VÁzQUEz DE PARGA, "Sudien zu Recopolis", p.259, nt.1. En Esspaña, por lo general, los topónimos tipo "griego, -s", son corrupciones de la voz céltica "briga" (=ciudad, fortaleza).

De Hispania Visigoda

Hispania Sacra 48 ( 1996$)$ 
sede metropolitana a Toledo, convertida ahora en capital de la provincia Cartaginense. En dicha ocasión, al discutirse el error de Eufemio, el decreto sinodal, además de mantener el status de ciudad regia para la ciudad del Tajo, sancionaba la indisolubilidad de los límites provinciales, estableciendo que la Carpetania no es sino una parte de la provincia Cartaginense:

- "nos eiusdem ignorantiae sententiam corrigimus, scientes proculdubio Carpetaniae regionem non provinciam esse, sed partem Carthaginensis provinciae, iuxta quod et antiqua rerum gestarum monumenta declarant." 22

Para el presente artículo, no obstante, interesa más otra mención a la Celtiberia transmitida en la Crónica de Juan de Bíclaro. La noticia a que hacemos referencia, fechada en el año 578, narra la fundación de la ciudad de Recópolis en el territorio celtibérico:

"Liuuigildus rex extinctis undique tyrannis, et pervasoribus Hispaniae superatis sortitus requiem propriam cum plebe resedit civitatem in Celtiberia ex nomine filii condidit, quae Recopolis nuncupatur: quam miro opere et in moenibus et suburbanis adornans privilegia populo novae Urbis instituit." ${ }^{23}$

La noticia de la fundación de Recópolis se encuentra recogida, asimismo, en las Historias de San Isidoro, si bien de forma mucho más escueta:

"...condidit etiam ciuitatem in Celtiberia, quam ex nomine filii sui Recopolim niminauit." 24

Esta nueva acción de gobierno, realizada después de superar las distintas rebeliones que amenazaban el control visigodo de la península, se enmarca dentro de un ambicioso programa que perseguía la unificación territorial y el fortalecimiento de la autoridad regia. Dentro de este contexto político se explican algunas de las más destacadas medidas de gobierno establecidas por el enérgico monarca que no pasaron desapercibidas a los cronistas de la época, dadas las importantísimas connotaciones ideológicas que conllevaban. La línea directriz del gobiemo de Leovigildo perseguía acentuar el carácter nacional del pueblo hispanogodo frente a las amenazas siempre latentes de sus peligrosos vecinos francos y bizantinos. Para ello era necesario forzosamente crear un vínculo que unificara a todos sus súbditos por igual, y Leovigildo creyó encontrarlo, a falta de una formulación política más elaborada, en el

${ }^{22}$ J. Vives Gatell, Concilios, p.407-410. Sobre este tema véase lo dicho por M. C. DiAZ Y DiAZ en la Introducción General a la edición de J. OROz RETA y M. A. MARCos CASQuero, San Isidoro de Sevilla. Etimologías. Madrid, 1982, p.31.

${ }^{23}$ Ioan. Bicl. Chronica, 578,4; ed. J. Campos, Juan de Biclaro, obispo de Gerona. Su vida y su obra. Escuela de estudios medievales. Estudios, vol. XXXII. Madrid, 1960, p.88 y 127-128.

${ }^{24}$ Isid. Hisp. Hist. Goth. c.5l; ES, V1, p.4I 4 y t.VII, p.71; C. RODRÍGUEZ ALONSO, Las Historias de los Godos, Vándales y Strevos de Isidoro de Sevilla. Estudio, edición crítica y tradtcción. León, 1975, p.90. 
credo arriano. Así, para el monarca visigodo, el arrianismo debía convertirse en la fides gothica, el instrumento político que serviría de ligazón ideológica a un reino heterogéneo.

Lógicamente, dicha medida estaba condenada a chocar con la realidad de un país mayoritariamente católico. El ideal de Leovigildo y las intrigas de la reina Gosvintha para alejar a Hermenegildo de la sucesión real provocarían * una cruenta confrontación civil que se resolvería, en principio, con el triunfo del monarca sobre el joven príncipe consors regni. Victoria mínima pues a la postre acabaría saldándose con la conversión de Recaredo y el pueblo de los godos al catolicismo. A pesar de ello, las medidas leovigildianas tuvieron un éxito más que notable, ya que, en realidad, la política de Recaredo puede considerarse una continuación de la de su padre, aunque bajo una óptica más acorde con la realidad religiosa del país ${ }^{25}$.

Entre las medidas destinadas al fortalecimiento del poder y la dignidad de la monarquía visigoda hay que resaltar de forma muy especial la copia del protocolo imperial, la acuñación de numerario sin subordinación al emperador y la potestad de fundar ciudades. Todos ellas eran facultades exclusivamente reservadas al basileus bizantino, esto es, al heredero legítimo de la dignidad imperial. En realidad, el hecho de ser ejercidas por un monarca bárbaro suponía en sí mismo la ruptura con la unidad imperial. Ciertamente, la unidad del Imperio era, a finales del siglo VI, una ficción simbólica, pero, en el fondo, constituía una peligrosa tutoría que dejaba las manos libres para una intervención militar bizantina, siempre dispuesta al amparo de una coyuntura favorable. La Italia ostrogoda y las consecuencias arrastradas tras la rebelión de Atanagildo, con la ocupación del levante y sur peninsular, planearon sin duda en la mente del monarca ${ }^{26}$.

La fundación de Recópolis entra de lleno, pues, en la práctica política de Leovigildo. El mismo nombre de la ciudad, de evidentes resonancias griegas ("la ciudad de Recaredo"), prueba la dependencia del monarca visigodo con respecto a los patrones políticos bizantinos.

\footnotetext{
${ }^{25}$ loan. Bicl. Chronica, 579,2-3; ed. J. Campos, p.89 y 128-134; L. A. Garcia Moreno, Historia de España visigoda. Madrid, 1989, p.120-129.

${ }^{2 \hbar}$ Sobre este tema véase Z. GARCía VıLLADA, Historia eclesiástica de España. t.II, la parte, Madrid, 1932, p. 42-77; J. Campos, Juan de Biclaro, p.81-139; J. ORLANDIS TORRES, Historia de España. t.IV, Epoca visigoda (409-7II). Madrid, 1987 (5a ed.) p.101-108; E. A. THOMPSON. Los godos en España. Madrid, 1985 (3* ed.) p.73-129; L. A. GARCía MORENo, Historia de España. p.113-143; P. J. GALAN SÁNCHEZ, La Chronica de Juan de Bíclaro: primera manifestación historiografica del nacionalismo hispano-godo. I Jornadas Internacionales "Los visigodos y su mundo". Ateneo de Madrid (inédito).

De Hispania Visigoda

Hispania Sacra 48 (1996)
} 
Fuera del problema de los límites provinciales de la Cartaginense, las citas en torno a la ciudad de Arcávica son de tipo indirecto y, en la mayoría de los casos, dependen de la localización exacta del monasterio Servitano. Comenzaremos, pues, con aquéllas que hacen mención explícita a la ciudad, para continuar después con las referencias a la fundación del monasterio Servitano, a pesar de que cronológicamente haya que situar la llegada de Donato y sus monjes en un momento algo anterior.

\section{Eutropio de Valencia}

Se conservan dos cartas escritas por el obispo de Valencia Eutropio ${ }^{27}$, cuando aún era abad del monasterio Servitano, dirigidas ad Petrum papam, que no es otro, según San Isidoro, que Petrum episcopum Ircauicensem ${ }^{28}$. La primera de ellas es un centón de Casiano que lleva el curioso título de De octo vitiis y que es, sin embargo, posterior a otra, mucho más interesante por lo que respecta a nuestro tema, titulada De dictrictione monachortum. Se supone que esta última carta fue escrita hacia el año $580^{29}$.

Es importante resumir el contenido de la misma para comprender su importancia desde el punto de vista arqueológico: se trata de una justificación del abad Eutropio ante el obispo Pedro de Arcávica defendiếndose de la acusación de dureza de que ha sido objeto por parte de los monjes de su comunidad. El hecho mismo de esta exculpación y el propio tono de la carta están en consonancia con la sumisión disciplinaria que tenían los abades respecto a su obispo. Este dato resulta fundamental para probar que el monasterio Servitano estuvo localizado efectivamente en la diócesis de Arcávica, puesto que es al obispo de esta ciudad, esto es, a su diocesano, a quien va dirigida la misiva ${ }^{30}$.

\footnotetext{
27 L. A. García Moreno, Prosopografía, n³66, p. 147.

${ }^{28}$ Isid. Hisp. Vir. illust. XLV: ES, V, p.447 = C. CODONEER MERINO, El "De viris illustribus" de Isidoro de Sevilla. Estudio y edición crítica. Salamanca, 1964, c.XXXII, p.152 (desde ahora, Isidoro de Sevilla): "<Eutropius> Scripsit et ad Petrum, episcopten Ircavicensem, de districtione monachorum salubri sermone compositam epistolam, el ualde monachis necessariam."; véanse también, $M$. C. DIAZ Y DíaZ, La producción literaria de Eutropio de Valencia. Anecdota Wisigothica, 1. Universidad de Salamanca, 1958, p.12. Sobre este obispo: ES, VII, p.72-74 y L. A. García Moreno, Prosopografia, $\pi^{\circ} 296$, p.131-132.

${ }_{29}$ Ambris cartas están editadas por M. C. DIAZ Y DíAZ, La producciôn literaria, p.20-26 y 27 35. Sobre látótonología de las mismas, p.17-18.

3. FEŔNÁNDEZ AlONSO, La cura pastoral en la España romanovisigoda. Roma, 1955, p.502; C. Codoñer MERINo, Ildefonso de Toledo, p. 50. Sobte las relaciones entre monncato y obispados es fundamental la obra de A. LINAGE CONDE, Los origenes det monacato benedictino en la Península Ibérica, t.I. El monacato hispano prebenedictino. Leon, 1973, p.224-227, quien utiliza el testimonio de Eutropio como ejemplo de sumisión ante el obispo: ("Haec tibi, beatissime pater, propierea suri-
} 
A este respecto, merece la pena transcribir la opinión de uno de los mejores conocedores del tema: "No encierra novedad el hecho de que los monasterios se hallaran sometidos en cierto grado a la potestad episcopal y que el obispo tuviera una determinada intervención en la vida de los que estaban enclavados dentro de los límites de su propio territorio: el obispo... convocaba y presidia los sínodos abaciales establecidos por la disciplina galicana de los siglos V y VI; y en la legislación de la Iglesia visigótica, las relaciones entre obispos y monasterios constituyen un problema repetidamente abordado por los concilios, que mantendrán el principio de una moderada intervención de la autoridad episcopal en la vida monástica..." ${ }^{31}$. La jurisdicción episcopal sobre los monasterios dependientes de su diócesis está ampliamente atestiguada en tiempos algo posteriores. Así, el canon 53 del IV Concilio de Toledo prescribe normas muy precisas para el control de los monjes errantes y su posible inclusión dentro del clero, bien monástico o secular, por decisión episcopal:

"Religiosi vivi propriae regionis qui nec inter clericos nec inter monachus habentur, sive hi qui per diversa loca vagi feruntur, ab episcopis in quorum conventu conmanere noscuntur licentia eorum coerceatur, in clero aut in monasterii deputati, praeter hos qui ab episcopo suo aut propter aetatem aut propter languorem fuerint absoluti. ${ }^{132}$

Hay que rechazar, por tanto, las antiguas reducciones del Servitano a Saitabi (Játiva) y al monasterio de San Martín citado por Gregorio de Tours, situado tradicionalmente entre Sagunto y Cartagen ${ }^{33}$, para localizarlo, sin duda

\footnotetext{
bimus, ut scias nos nihil absque ratione genere, sed secundum consuetudinem monasterii huitus quae sancte et regulariter instituta sunt facere.") y como prueba de que el monasterio hubo de estar en Arcávica: p.261, nt.255 (ta cita de Eutropio, en M. C. DíAZ Y DíAZ, La producción literaria, p.26, líneas $167-169)$

${ }^{31} \mathrm{~J}$. ORLANDIS TORRES, "Las congregaciones monásticas en la tradición suevo-gótica". AnEstMed 1 (1964) p.101. Del mismo modo, M. C. DiAZ Y DiAZ, "El erenitismo en la España visigótica," RevPortHist 6 (1964) p. 10, nt.19. La jurisdicción episcopal sobre los monjes se deduce del canon 53 del IV Concilio de Toledo y como tal se aplica en el caso de Valerio del Bierzo para la ordenacíón de Juan como presbítero. También Pérez de Urbel pensó en la ubicación del Servitano en Arcávica por esta razón, aunque errase en la localización de ésta; Los monjes españoles en la Edad Media. Madrid, 1934 ( $2^{\circ}$ ed.) t.I, p.203-205. Con todo to dicho anteriormente, no comprendemos, sin embargo, por qué Puertas Tricas niega este argumento que nos parece fundamental: Iglesias hispánicas (siglos $N$ al VII). Testimonios literarios. Madrid, 1975, p.29. Sobre el sentido claro de sometimiento al obispo de la carta, nos remitimos a lo dicho en la nota anterior.

${ }^{32}$ M. C. DIAZ Y DIAZ, "El eremitismo", p.10, nt.19.

${ }^{33}$ ES, VIII, p.57-62; A. LINAGE CONDE, Los origenes del monacaro benedictino, p.261. La reducción del Servitano a tierras del Levante es un lugar común entre la mayorín de los historiadores, incluso en fechas recientes: A. MUNDÓ, "1l monachesimo nella penisola iberica fino al secolo VII. Questioni ideologiche e letterarie", en SettstudaltMed Spoleto, 1957, p.83; E. Sánchez Salor, "La cultura en los monasterios visigodos", II Senana sobre al Monacato. CentEstRom. Aguilar de Cam-
}

De Hispania Visigoda

Hispania Sacra 48 (1996) 
alguna, en tierras alcarreñas, más exactamente, en Arcávica. Esto es más verosímil si se tiene en cuenta la tendencia general de la época, caracterizada por un desplazamiento progresivo de los centros vitales -políticos, económicos y culturales- desde la periferia al centro de la Meseta. En ello habría que ver probablemente la confluencia de varios factores, especialmente la consolidación de la monarquía goda en torno a Toledo, el auge de los intereses ganaderos y el progresivo hundimiento de los centros italianos que comerciaban con el levante y el suroeste español. Todo esto encuentra su reflejo en la pérdida de la primacía cultural de Mérida en favor de Toledo a lo largo de la séptima centuria $^{34}$.

Indudablemente, las ideas de lograr una mayor eficacia en el control del territorio y una cierta estabilidad política debieron estar en la mente de Leovigildo en el momento de adoptar la decisión de dividir el reino en el año 573. La división otorgaba a sus hijos Hermenegildo y Recaredo el control de la Bética y la zona levantina respectivamente con el título de corregentes, lo que presenta cierta semejanza con las circunstancias que rodearon su ascensión al trono de la mano de Liuva:

"duosque filios suos ex amissa coniuge Hermenegildum et Recaredum consortes regni facit ${ }^{\prime 35}$.

La ubicación del monasterio Servitano en Arcávica sirve además, como ya señaló Díaz y Díaz, para explicar satisfactoriamente el destacado papel desempeñado por el abad Eutropio en la organización del III Concilio de Toledo -el más importante de los celebrados y quizá el acto más decisivo de la Historia de España- junto a San Leandro, el obispo de la ciudad que había sido centro de la rebelión de Hermenegildo, algo que podría resultar chocante en principio tratándose, como es el caso, de un simple $\mathrm{abad}^{36}$. Eutropio no firma las actas del sínodo, puesto que hasta el VIII Concilio de Toledo no les está permitido a los abades intervenir sino como procuradores. En realidad, su participación en los concilios más que una situación de privilegio indica, por el contrario, un testimonio de la obligatoriedad para los abades de los monas-

pó, 1989, p.25-26; C. CODONER MERINo, La Literatura, en HistEspMenPid. Jover Zamora, t.II **, España visigoda. Madrid, 1991, p.238.

${ }^{34}$ J. M. LACARRA, "La Península Ibérica del siglo VIJ al X: centros y vías de irradiación de la civilización", en SettstudaliMed Spoleto, 1964, p.237-239. 16.

Ioan. Bicl. Chronica, a.573,5; ed. J. CAMPOS, p.83; M. C. DIAZ y DIAZ, Introducción, p.15-

${ }^{36}$ loan. Bicl. Chronica, 590,1: "summa tamen synndalis negorii penes sanctum Leandrum His. palensis ecclesiae Episcopum et beatissimum Eutropium monasterii Servitani abbatem fuit" ${ }^{t}$; ed. J. Campos, p.97-98 y 148. El año de celebración del Concilio es el 589 (sobre cl cómputo de años del Biclarense véase lo dicho en p.61 -68); en el mismo sentido, J, PÉREZ DE URBEL, Los monjes españoles, t.I, p.203-204. 
terios cercanos a la urbs regia de asistir a los sínodos. Incluso en aquellos casos en que aparecen consignados determinados abades como firmantes de las actas conciliares, sus firmas se encuentran agrupadas detrás de las signaturas de los obispos, por delante de los vicarios episcopales y magnates laicos ${ }^{37}$. Todo ello viene a confirmar de alguna manera que la actuación de Eutropio en el III Concilio toledano es una excepción hecha por alguna razón de capital importancia.

La situación del Servitano en las cercanías de Recópolis permite aventurar, como hipótesis plausible, la labor realizada por Eutropio como tutor del príncipe Recaredo en su conversión al Catolicismo; es decir, la misma función que tuvo el obispo hispalense con respecto a Hermenegildo. Ciertamente, de no aceptarse este papel rector, resultaría difícil explicar cómo un sencillo abad es equiparado al mismísimo metropolitano de Sevilla, por encima además de las más altas jerarquías religiosas del momento ${ }^{38}$. En idéntico sentido se expresaba Díaz y Díaz: "Tengo para mí que esta conversión (de Recaredo) fue el resultado, en lo privado, de una acción apostólica, llevada a cabo de tiempo atrás por Eutropio, abad del monasterio Servitano en la región levantina y luego obispo de Valencia, cerca de Recaredo cuando era corregente para las regiones de Levante, acción acaso paralela de la que poco antes había llevado a efecto Leandro en Sevilla con Hermenegildo. ${ }^{3}$

No obstante, aun cuando no cabe duda de que la tarea de organizar el sínodo toledano fuera un cargo honorífico de primera magnitud, la actuación del abad del Servitano no se agota aquí. Más bien parece representar un papel decisivo dentro de la política nacional del nuevo monarca en sus planes de reorganización del reino. Hay que suponer, por supuesto, que el mencionado abad contaría además con un prestigio intelectual muy superior al de otras personalidades de la época, especialmente por encima de su obispo Pedro de Arcávica. En caso contrario, Recaredo lógicamente se hubiera apoyado en éste.

El talento de Eutropio está plenamente confirmado en el elogio que le dedica el Biclarense, pues refiere que su figura brillaba en el III Concilio de

\footnotetext{
37 A. LINAGE CONDE, Los orígenes del monacato benedictino, p.229, recoge la tesis de Bishko, y en esto le sigue J. ORLANDIS TORRES, Abades y Concilios en la Hispania visigótica. Anrigüedad y Cristianismo, III. Los visigodos, Historia y Civilización. Murcia, 1986, p.221-233 (especialmente, p.227 y 230 ).

I8 J. PÉrez de URbel, Los monjes españoles, t.I, p.204, cree posible que conociern a Leovigildo y a Recaredo, puesto que Recópolis quedaba dentro de la diocesis de Arcŕvica (a peșar de situar la ciudad más al sur, en Cabeza de Grieg(o). Nos remitimos además a lo dicho en la nota anterior a propósito de la actuación de los abades en los Concilios hispanovisigodos.

${ }^{39}$ M. C. DiAZ Y DiAZ, Intioduccion, p.2 1, nt.43. En general, puede verse un resumen muy acertado de la circunstancia histórica en dicha obra: p.11-30.
} 
Toledo, el sínodo de Leandro y Másona, "quasi stella matutina in medio nebulae", y con razón comenta Campos que "Grande y bien fundamentado debía estar su prestigio cuando habiendo en aquel gran concilio tantos ilustres obispos y abades, se le encargó a él con $S$. Leandro 'summa synodalis nego$t i i^{\prime \prime}{ }^{40}$. Las obras literarias que se le atribuyen y el hecho de que el monasterio gozara de una excepcional biblioteca (que no sólo hay que suponer importante en cuanto al volumen de códices custodiados, sino en la calidad y novedad de éstos), apuntan también en la misma dirección ${ }^{41}$. Otros datos a tener en cuenta, anotados ya en su día por Codoñer, son la actuación de los monasterios como centros de formación de los cuadros dirigentes eclesiásticos en la España visigoda (lo que podría explicar la relación de Eutropio y Liciniano de la que luego hablaremos), así como la posibilidad de una relación de origen entre el Servitano y el toledano monasterio de Ágali, muy vinculado a la corte regia, que podría explicar el interés de San Ildefonso por recoger la noticia sobre la vida de Donato ${ }^{42}$.

Interesante es también la serie de cartas cruzada entre el abad del Servitano y el obispo de Cartagena, ciudad que en esta época, no se olvide, se encontraba ocupada por los ejércitos bizantinos:

"Lucinianus Carthaginis Spartariae episcopus, in Scripturis doctus: cuius quidem multas epistolas legimus, de sacramento denique baptismatis unam, et ad Eutropium abbatem, qui postea Valentiae episcopus fuit, plurimas." ${ }^{43}$

Orlandis ${ }^{44}$, siguiendo a Madoz ${ }^{45}$, explica esta relación epistolar suponiendo la probabilidad de que el obispo de Cartagena hubiera sido monje del monas-

41' loan. Bicl. Chronica, 590,1; ed. J. CAMPOS, p.97-98, 140 y 148 . Téngase en cuenta que era discípulo de Donato y que a éste se le ha señalado como parte fundamental del renacimiento isidoriano por un autor tan competente en la materia como J. FONTAINE, El prerroménico. La España románica, vol. VIII. Madrid, 1978, p.127-128.

41 E. SÁNÇHEZ SALOR, "La cultura en los monasterios", p.25-26, destaca el importante papel jugado por los monjes emigrados del norte de África en la aportación de fondos bibliográficos y, quizás también, de manuales escolares, señalando entre los principales del siglo VI al monasterio Servitano, junto a los de Asán y Dumio.

${ }^{42}$ C. CODONER MERINo, Idefonso de Toledo, p.51 y La Literatura, p.238.

${ }^{43}$ Isid. Hisp. De vir, illust. XLIF; J. Madoz, Liciniano de Cartagena y sus cartas. Edición critica y estudio histórico. Madrid, 1948, p.9.

44 J. ORLANDIS TORRES, La Iglesia en la España visigólica y medieval. Pamploná, 1976, p.205.

45 J. MADOz, Liciniano de Cartagera. p.15-16. Indica también la posibilidad, más remota, de que fuera monje del monasterio de San Martín de la isla Ferraria. De ser efectivamentc discípulo de! Servitano, habría que sumar también el nombre del obispo Severo de Málaga, "collega ef socius Liciniani Episcopi", entre las personalidades educadas en el monasterio arcavicense: p. I2 (Isid. Hisp. De vir. Illtst. XLIl]: ES, V, p.446; C. CODOÑER MERINo, Isidow de Sevilla, XXX, p.i5I). Esto reforzaría la idea del Servitamo como gran centro cultural y la de su situnción cercana a un centro aúlico como es Recópolis. 
terio Servitano. Este original planteamiento puede arrojar mucha luz sobre la relación epistolar mantenida por Eutropio con Liciniano, paralela a la que mantuvieron el metropolitano de Cartagena y San Leandro de Sevilla. Esta correspondencia parece enmarcarse dentro de los esfuerzos de Recaredo por encontrar una solución pacífica que pusiera fin a la ocupación bizantina del levante peninsular. La actuación de Eutropio en los proyectos políticos de Recaredo pone de relieve la importancia del personaje en cuestión dentro de los planes reorganizadores del nuevo monarca y, sin duda, a ello debe su posterior nombramiento como obispo de Valencia. Finalmente, el asesinato de Liciniano en Constantinopla dió al traste con los intentos del monarca que, incluso, había llegado a apelar a la mediación papa ${ }^{46}$.

El abad Donato y la fundación del Servitano

Por lo que se refiere a la fundación del monasterio Servitano, ésta nos es conocida gracias a una noticia recogida profusamente (dentro de la habitual parquedad de las fuentes visigodas) por el obispo Ildefonso de Toledo. Merece la pena citarla textualmente, dada la importancia capital de la misma para nuestro estudio:

"Donatus et professione et opere monachus cuiusdam eremitae fertur in Africa extitisse discipulus. Hic uiolentias barbararum gentium imminere conspiciens atque ouilis dissipationem et gregis monachorum pericula pertimescens, ferme cum septuaginta monachis copiosisque librortm codicibus navali uehiculo in Hispaniam commeauit. Cui ab inlustri religiosaque femina Minicea subsidiis ac rerum opibus ministratis, Servitanum monasterium uisus est construxisse. Iste prior in Hispaniam monasticae obseruantiae usum regulamque dicitur aduexisse. Tam uiuens uirtutum exemplis nobilis quam defunctus memoriae claritate sublimis. Hic et in praesenti luce subsistens et in cripta sepulchri quiescens, signis quisbusdam proditur effulgere salutis, unde et monumentum eius honorabiliter colere perhibentur incolae regionis. ${ }^{47}$

La noticia se puede fechar hacia el año 571 gracias al testimonio del Biclarense, quien sitúa la actuación de Donato en el tercer año del reinado de Leovigildo:

46 "Claruit temporibus Mauricii Augtstit occubuit Constantinopoli, veneno, ut ferunt, extinctus $a b$ aenulis..." Isid. Hisp. De vir. illust. XLII y XLV: ES, V, p.445-47; C. CODONER MERINO, Isidoro de Sevilla, XXIX y XXXII, p.150-152. Sobre esta hipotesis, véase C. CoDONEER MERINo, Ildefonso de Toledo, p.52-53 y nt. 130 .

${ }^{47}$ Hild. Tol. De vir. illist. III; C. CODOÑER MERINo, Ildefonso de Toledo, p.120-123.

De Hispania Visigoda

Hispanja Sacra 48 (1996) 

tur." 48

"Donatus, abbas monasterii Servitani mirabilium operator clarus habe-

El texto del obispo toledano, ya lo hemos comentado antes, es de suma importancia por muchos conceptos y, como veremos más adelante, su interpretación resulta fundamental para la comprensión de los datos arqueológicos. Por todos los interrogantes que plantea, no es extraño que la totalidad de los autores que se han ocupado del monacato hispano antiguo haya reparado en él ${ }^{49}$.

El primero de los problemas que suscita se refiere a la noticia de que fue este abad quien introdujo en España la costumbre de aplicar una regla, algo que contrasta con lo que conocemos por las fuentes, pues, entre otros testimonios, el Concilio de Zaragoza celebrado en el año 380 legisla ya sobre esta materia. Anscari Mundó apuntó la posibilidad de que la regla introducida por Donato fuera, en realidad, la de San Agustín, basándose tanto en su origen norteafricano como en el papel desarrollado por su sucesor Eutropio en el III Concilio de Toledo, así como por la relación de éste con Leandro de Sevilla, cuya De institutione virginum parece ser una adaptación de la doctrina ascética del Hiponense ${ }^{50}$. Linage Conde, no obstante, no se decide: por un lado, considera posible la hipótesis de Mundó, pero la rechaza por la imposibilidad de comprobarlo". Para este autor, "cuando Ildefonso nos habla genéricamente de la costumbre y la regla de la observancia monástica, está pensando con tanta intensidad en una regla y costumbre tan determinadas, que se permite inconscientemente el lajo de sobreentenderlas... Ello nos prueba que el monaquismo de Donato tuvo características específicas y que alcanzó en la península una gran difusión... Esta regla sería, según lo dicho anteriormente, original, no la de Agustín", y se pregunta si no pudo ser una adaptación de la vida monástica a los clérigos o a ciertas categorías de éstos ${ }^{52}$.

Sea como fuere, lo cierto es que, el problema no parece tener solución hoy por hoy, y esto se puede ver claramente en la diversidad de juicios sobre el tema, contradictorios a veces incluso dentro de un mismo autor. Es el caso concreto, por ejemplo, de Díaz y Díaz: en la introducción a su edición a las cartas de Eutropio se decide por la opinión de que la regla de Donato no esta-

\footnotetext{
${ }^{48}$ Ioan. Bicl. Chronica, 57/,4; ed. J. CAMPOS, p.81 (ES, VI, 384).

49 Z. GarCía Villada, Histeclesp, p.282; J. FernándeZ ALONSO, La cura pastoral, p.498-99; A. MUNDÓ, "Il monachesimo", p.83-84; A. LINAGE CONDE, Los orígenes del monacato benedictino. p. 261 y $267-268$.

"9. A. MUNDó, "Il monachesimo", p.83-84. La misma opinión comparte también C. CODoÑER MERINO, Ildefonso de Toledo, nt.124.

"II Una postura similar en Flórez: ES, VIIl, p.60.

52 A. LINAGE CONDE, Los origenes del mimacato benedictimo, p.261, nt.254 y p.266-267.
} 
ba fijada por escrito, tratándose tan solo "de una serie de hábitos encuadrados en una enseñanza oral, cuya interpretación y aplicación en cada caso concreto quedaba al arbitrio, a la sabiduría y a la prudenci del abad. ${ }^{153}$ En un trabajo posterior, sin embargo, este mismo autor parece considerar que existió efectivamente una regla de Donato, hoy perdida ${ }^{54}$.

En cualquier caso, aunque nos inclinemos favorablemente por la tesis de Mundó, precisamente por las razones expuestas por Linage Conde (las características específicas y la gran difusión que permitirían obviar su mención a San Ildefonso) ${ }^{55}$, esta insoluble cuestión no es, para nosotros, la principal. Más interesantes, desde nuestro punto de vista, son las conclusiones que se pueden extraer de otras frases de la narración del obispo toledano. En particular, la noticia de que Donato había sido discípulo de un eremita en África y que, a su muerte, fuera enterrado en una cripta sepulcral, donde su sepultura continuaba siendo venerada por los habitantes de la región, aún en el momento en que Ildefonso escribe su relato, hacia mediados de la séptima centuria ${ }^{56}$.

El testimonio de San Ildefonso es reafirmado por las noticias que anteriormente nos legara el Biclarense, en donde el fundador del Servitano aparece considerado como santo:

"Donatus, abbas monasterii Seruitani mirabilitum operator clarus habetur"; "Eutropius abbas Monasterii Sertitani discipulus S(ancti) Donati clarus habetur. ${ }^{\text {"57 }}$

La concepción de Donato como vir Dei que llega a trascender incluso a su muerte terrena, después de la cual continúa obrando milagros a través del culto a sus reliquias, es muy significativa; sobre todo porque, como bien ha señalado el insigne investigador francés J. Fontaine, "desde el desarrollo de los temas taumatúrgicos en las biografias ascéticas... no se concebia santidad que no se acompañara y manifestara por los poderes sobrenaturales de hacer

\footnotetext{
${ }^{53}$ De dictr, monach. líneas 126-134; M. C. DlAZ Y DIAZ, La producción literaria, p.25 y 13.

34 M. C. DiAZ Y Díaz, Introđucción, p.45 nt. 117.

ss Nos basamos tanto en el origen norteafricano del abad y sus monjes, como en que lldefonso parece hablar de una Regla conocida, por lo que no entra a detallar cuál. Además, hay que tener en cuenta la opinión de C. CoDoÑER (IIdefonso de Toledo, p.66) de que el uso del impersonal dicitur indicaría un intento de evadir el compromiso sobre la veracidad de la noticia y situarla en el terreno de la tradición. Asś, lo que interesaría al obispo toledano no es tanto precisar la veracidad del dato como aumentar la fama del santo.

${ }^{56}$ Hild. Tol. De vir. illust. 1l!; C. CODOÑER MERINO, Ildefonso de Toledo, p.120-123; C. García Rodríguez, El culto de los santos en la España ronana y visigoda. Madrid, 1966, p.348; R. PUerTas Tricas, Iglesias hispánica.r, p.28; I. G. BANGo ToRviso, "El espacio parn enterramientos privilegiados en la arquitectura medieval española." AnDepHistTerrArt 4 ( 1992) p.105, nt.59.

${ }^{s 7}$ Ioan. Bicl. Chronica, 571,4 y 584,5 respectivamente; ed. J. CAMPos, p.81, 92 y 140. Véase también lo dicho por FLóREZ, ES, VIII, p.60-6I.
}

De Hispania Visigoda

Hispania Sacra 48 (1996) 
milagros ${ }^{458}$. Desde esta óptica, los restos de Donato se presentan ante la mentalidad popular dotados de un carácter milagroso: "se trata de milagros operados por sus reliquias, comparable a cuantos nos cuenta Gregorio Turonense en la Galia..." 59. De esta forma, no es extraña la veneración local de su sepultura que constata el Toledano y que puede parangonarse con otros episodios similares de monjes-eremitas bien conocidos, como, por ejemplo, San Millán en la Rioja o San Frutos en el Duratón ${ }^{60}$.

En cuanto a la fecha de la muerte del abad Donato, sabemos que ésta debió producirse entre los años 571, en que sitúa la narración Juan de Bíclaro, y el 584, momento en el que Eutropio aparece como su sucesor al frente del Servitano $^{61}$. De aceptarse la cronología que propone Díaz y Díaz para la redacción de las cartas de Eutropio, este lapso se podría acortar en cuatro años, hasta $580^{62}$.

Fuera ya de los testimonios referidos a Donato y Eutropio, Arcávica queda prácticamente relegada al olvido de las fuentes, si se hace excepción de los obispos signatarios en los Concilios toledanos ${ }^{63}$. Como parte integrante de la antigua provincia Cartaginense, encontramos la firma del obispo Teodosio en el Sínodo reunido por Gundemaro en el año 610 con el fin de la aceptación de Toledo como sede metropolitana ${ }^{64}$. La última noticia de este tipo es la presencia del obispo Gabinio en los Concilios XV (a.688), XVI (a.693) y, quizás, en el $X V I I$, celebrado un año después que el anterior y del que no se conservan las firmas ${ }^{65}$.

Después de la invasión musulmana de 711, Sebastián, el último obispo de Arcávica, pasó a convertirse en el primer prelado de la recién restaurada sede de Orense. La ciudad había sido arrasada por los musulmanes, provocando la huida de Sebastián a Asturias en tiempos de Ordoño I, hacia mediados del

\footnotetext{
58 J. Fontaine "El De viris illustribus de San [1defonso de Toledo: tradición y originatidad." $A n$ Tol III (1971) p.80 y 82, nt.45; Y. DUVAL, Auprès des saints corps et âme. L'inhumation ad sanctos dans la chrétienté d'Orient et d'Occident de III at VIII siècle. EtAug (1988) p. 176-179.

59 J. FONTAINE "El De viris illustribus", p.81-82.

"Sobre estos dos santos véase lo dicho por F. Íñ Guez ALMECH, "Algunos problemas de las viejas iglesias españolas." CuadirabEscEspArq Roma, Vl]. Roma-Madrid, 1955, p.28-29; $\mathrm{M}^{2} \mathrm{~S}$. MARTIN POSTigo, San Frutos del Duratón. Historia de un Priorato benedictino. Segovia, 1970. p.26-27 y J. N. HiLloarTH, "Popular Religion in Visigothic Spain." en E. JaMES, E. (ed.) Visigothic Spain: new approaches. Oxford Clarendon Press, 1980, p.36-37.

${ }^{61} \mathrm{ES}, \mathrm{VIII}, \mathrm{p} .61$.

62 M. C. DIAZ Y DIAZ, La producción literaria, p.17-18.

6.7 ES, VII, p.72-79.

${ }^{6}$ Ibidem, VII, p.74; J. Vives Gateli, Concilios, p.403-410; L. A. Garcla Moreno, Prosopografia, $\mathrm{n}^{0} 297, \mathrm{p} .132$.

${ }^{6}$ ES, VIJ, p.74; 3. VIVEs Gatell, Concilios, p.449ss; L. A. García Moreno, Pro.opografia, $\mathrm{n}^{\circ} 302, \mathrm{p} .133$.
} 
siglo IX. Aparece citado como obispo de Orense hacia el año 866, siendo más difícil de fechar su muerte. Según la opinión del padre Flórez, le sucedió Censerico en el año 882, y a éste Sunna cuatro años después, pero, en opinión de Fita, en un documento de 885 todavía se le nombra como obispo. El privilegio de Alfonso III en el que se recoge la huida y posterior nombramiento de Sebastián dice textualmente:

"Adveniente quoque Sebastiano, Archabiensi peregrino episcopo ex provincia Celtiberiae expulso a barbaris, mirabiliter, hanc Sedem <Auriensem> illi concessimus; qui primus eiusdem ecclesie antistes fuit." ${ }^{66}$

Según el padre Fita, Sebastián sería el verdadero autor de la llamada Crónica de Albelda (compuesta hacia 883), mientras que la que se le atribuía de forma habitual sea realmente obra del rey Alfonso III $^{67}$. En realidad, parece ser que a este obispo se debe la llamada versión culta de la Crónica de Alfonso III o ad Sebastianum, una revisión erudita de la obra del Rey Magno ${ }^{68}$. En opinión de Sánchez-Albornoz, es posible además que estuviera emparentado con la importante familia muladí de los Banu Qasi, que gobernó el valle medio del Ebro durante este periodo, y quizás con Jimena, la esposa del rey asturiano, si ésta era en verdad hija de García Íñiguez ${ }^{69}$.

La huida del obispo es uno de los datos que sirven para fechar los materiales cerámicos del monasterio arcavicense ${ }^{7}$. Con posterioridad, las fuentes musulmanas inciden en el carácter belicoso y en las numerosas revueltas ante el poder cordobés de los bereberes asentados en la ahora llamada Santabariya, seguramente comupción árabe del apelativo Celtiberia con que se acompañaba el nombre de la ciudad en la época anterior ${ }^{71}$. El tema fue estudiado en su día por Torres Balbás y no nos extenderemos sobre el mismo por rebasar los límites de nuestro estudio, aunque necesita una revisión actualizada. Apuntemos, de paso, por lo extraño de la noticia, el testimonio de una incursión por tierras

\footnotetext{
${ }^{6 h}$ ES, VII, p.S2-54; F. FITA, "Sebastián, Obispo de Arcávica", p.333-336.

${ }^{67}$ Ibidem, p.336-337.

69 C. SÁNCHEZ AlboRnoz, Origenes de la Nación Espaĩola. El Reino de Asturias. Madrid, 1985, p.298-299; J. GlL Fernández,; J. L. MORAlejo y J. l. RuIz de LA PEÑA, Crónicas asturianas. Oviedo, 1985, p.33-36, 50-51 y p.229, nt.46.

${ }^{69}$ C. SÁNCHEZ ALBORNOZ, Orígener, p.281 y 298-299. La vinculación de! distrito arcavicense con gentes navario-aragonesas es posible rastrearla tanto en los testimonios históricos como en la toponimia de áreas cercanas. Así, Sancho Ramírez interviene en ln toma de Santaver por Ahmad ibn Sulayman ibn Hud: Ibn al-Kardabus, Historia de al-Andalus, 40. ed. F. MAf́llo SALGADO. Madrid, 1986, p.101. En cuanto a la toponimia de repoblación de la zona hay que resaltar nombres como el de la Sierra de Bascuñana o el del cercano pueblo de Gascueța.

70 Y. Álvarez Delgado, Cerámicas comunes, p.41li-4li2.

7 P. BELTRAN, "Segóbriga", p.245.
} 
de Santaver de los Mayus (paganos) fechada en el año 971 y recogida en los Anales califales:

"El sábado 25 de dicho mes de ramadán [ 22 julio 971$]$ entró en Córdoba Silis [=Ziniz?], embajador del Conde Gundisalb ibn Munio, con una carta de éste, desde la ciudad de Astorga, en los confines de Galicia, fechada el domingo 12 de ramadán $[=9$ julio $97 I]$ dando cuenta de que, el sábado an-

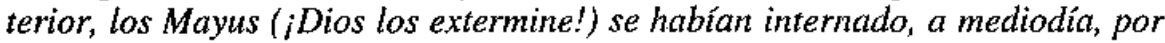
el rio Duero y habían hecho una incursión hasta Santaver y su llanura, de la que volvieron sin lograr nada. ${ }^{72}$

La noticia, llegada desde la ciudad de Astorga a la corte cordobesa de alHakam II por medio de un embajador del conde Gundisalbo Muñoz, parece referirse a un ataque efectuado por piratas normandos. Con razón se extraña algún autor ${ }^{73}$ de la posibilidad de un ataque vikingo por tierras alcarreñas: en realidad, la explicación más factible podría ser que el topónimo Santaver se refiera a la Meseta en sentido amplio, si se acepta -como parece muy probable- la derivación Santabariya a partir de Celtiberia que antes se ha comentado. A esto aludiría la mención a su llanura. De otra forma no se explicaría que una incursión por el Duero llegue hasta la misma Arcávica, más aún cuando esta ciudad está ubicada en la cuenca del Tajo y muy alejada de la costa occidental de la península.

El hecho de que la incursión tenga lugar por el Duero y que el aviso provenga del conde de Astorga despeja cualquier posible duda de que se trate de una de las típicas confusiones de las fuentes musulmanas entre Santabariya y alguna de las Santa Mariyya que existen: la de oriente, con capital en Albarracín y la de occidente, con Faro como sede ${ }^{74}$. Esta explicación concuerda bien, además, con la ruta tradicional seguida por los normandos de camino hacia Bizancio, que obligaba a expediciones, por lo general, cercanas a la costa. En este contexto hay que incluir la embajada de Gundisalvo Muñoz: se trata de un aviso a los andalusíes para que se preparen ante un eventual ataque vikingo $^{75}$. La noticia de al-Razi, por su parte, parece indicar, eso sí, una incursión de mayor envergadura, seguramente traspasando los límites del actual Portugal, pero sin que existan motivos para creer que ésta llegara hasta tierras conquenses.

\footnotetext{
${ }^{72}$ Anales Palatinos del Califa de Córdoba al-Hakam H, por 'Isa ibn Ahmad al-Razi (360-364 $H .=971-975 J . C$.$) ; ed. E. GARCli Gómez. Madrid, 1967, p.50.$

73 J. ZOZAYA STABEL-HANSEN, "Razzias vikingas en la España islámica." Revarqueo 6 (abril,1981) p.39.

${ }_{74}$ Ibn al-Kardabus, Historia de al-Andahtss, 35; ed. F. MAílLO, p.97, nt. 147.

75 J. ZOZAYA STABEL-HANSEN, "Razzias vikingas", p.39-40.
} 


\section{LOS HALLAZGOS ARQUEOLÓGICOS}

Los restos arqueológicos de la Arcávica visigoda se sitúan en tres zonas diferentes del yacimiento. Una primera está configurada por el llamado "eremitorio", la necrópolis aneja y el pocillo, que conforman un importante área arqueológica situada en torno a la ladera sur del Castro. Una segunda zona la constituyen los restos de un gran edificio levantado con sillares y tradicionalmente interpretado como un monasterio. Esta gran construcción se sitúa algo apartada hacia el sureste con respecto a la anterior. Por último, se encuentra la necrópolis de La Rinconada, área cementerial situada al pie del cerro, en pleno valle del Guadiela, hacia el norte del yacimiento.

\section{El Monasterio}

El monasterio se halla situado en el despoblado de Santaver, en el área conocida también como Vallejo del Obispo, a unos $2 \mathrm{~km}$. aproximadamente de la ciudad romana. El emplazamiento elegido resulta idóneo por cuanto domina el valle y a la vez se encuentra a poca distancia del río Guadiela, si bien lo suficientemente alejado de él como para evitar los problemas de insalubridad y humedad que conllevaría una excesiva cercanía.

Desgraciadamente, a pesar de la importancia de los trabajos efectuados en la zona ${ }^{76}$, éstos no se han visto acompañados de un aparato bibliográfico similar. El yacimiento medieval ha sido objeto tan solo de tres publicaciones, dos de ellas sobre las cerámicas del siglo $\mathrm{IX}^{77}$ y un tercero sobre las estelas discoideas aparecidas en una de las necrópolis ${ }^{78}$.

Las sucesivas campañas de excavación han puesto al descubierto un gran edificio que se extiende sobre una superficie de $50 \times 45 \mathrm{~m}$., lo que representa un área de $2.250 \mathrm{~m}^{2}$. El edificio original, del que sólo se conservan las subestructuras, presenta una técnica constructiva bastante homogénea, con muros de unos dos metros de grosor construidos mediante dos hiladas de sillares colocados a hueso con relleno del espacio intermedio mediante piedras y tierra ${ }^{79}$.

\footnotetext{
${ }^{76}$ Se realizaron campañas de excavación en los años 1974-75 bajo in dirección de MANUEL OSUNA RUIZ; en 1981, dirigida por CARLOS MONCó GarCía y YaSMINA Álvarez DELGADO, y en el período 1982-88, por CARLOS MONCÓ GaRCÍA y AMELIA JiMÉNEZ PÉREZ.

${ }^{n}$ Y. Álvarez Delgado, Cerámicas comunes, p.404-412 y "Cerámicas del siglo IX", p. 109 122.

${ }^{7}$ C. MONCÓ Garcta y A. JiMÉNEZ PÉREZ, Las estelas discoideas, p.534-543.

79 Este tipo de construcción se encuentra bien documentado en época romana, perdurando hasta momentos muy posteriores: TH. HAUSCHild, Técnicas y maneras de construir en la arquitectura paleocristiana hispánica. II RArqPalHisp. Montserrat, 1978 (Barcelona, 1982). Por otro lado, se 
Los materiales de construcción han sido reutilizados en su mayor parte de la cercana ciudad romana. EJ hecho de que la fábrica de esta construcción se haya realizado mediante grandes sillares de arenisca acerca este edificio a las basílicas baleares y a las iglesias de la segunda mitad del siglo VII ${ }^{80}$.

La trama original de este edificio se encuentra bastante modificada como consecuencia de las sucesivas reutilizaciones del mismo, sin que podamos contar con una planimetría detallada hasta la publicación de las conclusiones definitivas por parte de sus excavadores. Sin embargo, por lo publicado hasta Ia fecha, se puede hablar de tres zonas bien diferenciadas: una gran estructura rectangular que ocupa la parte noreste del edificio, posteriormente reutilizada como iglesia; otra gran sala, asimismo rectangular, orientada este-oeste, que se interpreta como la cilla mozárabe y que, presumiblemente, sea también la original visigoda, algo modificada. Por último, hay que reseñar la aparición de una serie de recintos de $3 \times 3 \mathrm{~m}$., que se interpretan como celdas monacales ${ }^{81}$. Esta particularidad parece apuntar hacia una planta centralizada o cuando menos bien organizada, reflejo material del amplio desarrollo alcanzado por el monacato en la España visigoda. El monasterio arcavicense se presenta, pues, como un posible eslabón entre los grandes centros monásticos norteafricanos y los carolingios de época posterior.

De este primitivo cenobio, como ya se ha señalado, apenas quedan restos de sus estructuras y algunos materiales de su primer momento, plenamente visigodo. Entre ellos, un fragmento de pilastra decorada con racimos de vid y parte de un broche de cinturón tiriforme. En las cercanías del mismo, en la ladera sur del Castro, se encontraron también dos fragmentos pertenecientes a un cancel calado con decoración de tetrafolias formadas por círculos secantes $^{82}$. Las dos primeras piezas han sido en parte amortizadas: la pilastra ha sido

documentaron algunos muros con restos de enlucido, algo que debió ser frecuente en época visigoda, como sucede, por ejemplo, en la vecina ciudad de Recópolis: L. CABALLERo ZOREDA, Pervivencia de elementos visigodos en la transición al mundo medieval. Planteamiento del tema. III CAME. Oviedo, 1989 , p. 121

TH. HAuschILD, Técnicas y maneras de construir, p.84, donde parece insinuar un origen nọteafricano o mediterráneo en general; A. ARBEjTER, Construcciones con sillares. El paulatino resurgimiento de una técnica edilicia en el reino visigodo de Toledo. IV RArqPalHisp Lisboa, 1992 (en prensa).

${ }^{81}$ Los paralelos podrían encontrarse en el Norte de África: A. M. MARTínez TejerA, Aproximación a la arquitectura monástica hispana de época visigoda según las fuentes literarias. I Jornadas Internacionales "Los visigndos y su mundo". Madrid-Toledo, 22-24 Noviembre, 1990 (inédito).

${ }^{82}$ Las piezas caladas no suelen ser habituales dentro de la plística hispanovisigoda, si bien se conocen algunos ejemplos, especialmente de cruces (en Alconétar, Plá de Nadal o en la misma Arcávica) y de placas de cancel que seguramente actuarían a modo de iconostasis, como la de Recópolis del M.A.N.: L. VAZQUEZ DE PARGA, "Studien zu Recopolis", fig.6. Esta pieza parece poner en evidencia de nuevo la relación de este centro con Arcávica. 
recortada ${ }^{83}$ y el broche aparece partido por la mitad ${ }^{84}$. Del monasterio o de otro gran edificio situado en sus cercanías deben proceder también dos capiteles corintios de hojas de acanto estilizadas ${ }^{85}$, cuyos paralelos más cercanos se encuentran en Toledo ${ }^{86} \mathrm{y}$, sobre todo, en el área del sureste. En efecto, se han encontrado dos capiteles en La Toscana (Jaén) y otro más en La Alberca (Murcia) prácticamente idénticos a los arcavicenses e, indudablemente, obra de un mismo taller levantino ${ }^{87}$. El estilo menos esquemático de estos ejemplares delata una cronología ligeramente más antigua que los toledanos, quizá de la primera mitad del siglo VII o, incluso, algo anterior, de finales del siglo VI.

Volviendo de nuevo al monasterio, la cilla parece que fue modificada después de su construcción, compartimentándose en dos recintos al construirse un muro de mampostería con piedras colocadas a hueso en su eje longitudinal. Estos dos pasillos proporcionaron abundantes restos arqueológicos que atestiguan el abandono rápido del lugar, puesto de manifiesto además por las huellas de incendio y destrucción del edificio. Entre el material documentado, merece destacarse por su importancia una serie de cestos de esparto que se encontraron con su contenido carbonizado (nueces, centeno, trigo y almendras). Esto, unido a la aparición de utensilios como ruedas de molino, etc., hace pensar en un área de almacén y despensa donde se realizarían los trabajos auxiliares de cocina y molienda.

${ }^{83}$ El tema de la vid es típico del arte paleocristiano, bizantino y visigodo, donde pasa a simbolizar el misterio eucarístico (Hild. Tol. De ithere deservi, XXXI; J. Campos RuIz y V. BLANCo, Santos Padres españoles. Madrid, [971, t.I, p.40I). El motivo del tallo ondulado alternando hojas de vid y racimo parece original del ámbito georgiano y sirio, de donde pasó a Bizancio y Occidente: véase W. D. Zizichwilli,"Antecedentes de la decoración visigoda y ramirense." AEspArt 27 (1954) p.141-144. Hay paralelos de esta pieza en algunos relieves procedentes de una de las basflicas de Cabeza de Griego, hasta el momento inćditos, que esperamos publicar en breve. Ejemplares como éste de Arcávica se fecharían en la séptima centuria.

${ }^{84}$ Se trata de un broche de perfil liriforme característico del siglo VII, con abundantes paralelos morfológicos en toda la península. Piezas similares se encuentran abundantemente documentadas en Cuenca: M. Lopez Requena y R. BARroso CABrera, La necrópolis de La Dehesa de la Casa. Una aproximación al estudio de la época visigoda en la provincia de Cuenca. Madrid, 1995, p.59-61.

${ }^{85}$ Uno de ellos está publicado y se sabe que apareció en la superficie de la zona romana del yacimiento: M. Osuna RuIz et al. Catálogo del Museo de Cuenca. Cuenca, 1983, p.58-59, lám.XXXVIII; E. DOMÍngUez PERELA, Capiteles hispánicos altomedievales. Universidad Complutense de Madrid, tesis 40/87, Madrid, 1987, t,Il, p.407. El otro ejemplar es idéntico y parece que procede del mismo monasterio: Y. Álvarez DeLGaDo, Cerámicas comunes, p.405. Todos los materiales aquí citados se encuentran depositados en el Museo Provincial de Cuenca.

${ }^{86}$ I. Zamorano Herrera, "Caracteres del arte visigodo en Toledo." AnTol 10 (1974) p.l27128; J. J. STORCH DE GRAClA Y ASENSIO, Las artes decorativas visigodas en Toledo. Tesis de Licenciatura. Univ. Complutense de Madrid, 1983 (Microficha) p.42-44.

${ }^{87}$ M. CoRChado Sokiano, "Hallazgos en La Toscana (Jaén)", ArchEspa 41 (1968) p.154-159.

De Hispania Visigoda

Hispania Sacra 48 (1996) 
Los materiales cerámicos aparecidos en dicha estancia fueron objeto de un estudio realizado por Yasmina Álvarez Delgado, quien llegó a diferenciar dos tipos de cerámicas: un primer tipo de cocina y almacén, y otro de mejor acabado y formas más elaboradas que correspondería a la vajilla de mesa ${ }^{88}$. Las primeras seguirían la tradición visigoda, que puede retrotraerse incluso a épocas anteriores y que se muestra visible sobre todo en ollas, tinajas, orzas y algunas jarras. Estas cerámicas pueden adscribirse a un grupo mozárabe. Junto a esta producción, la más numerosa, existe también un pequeño grupo de formas y decoración islámicas, entre las que se incluyen algunas cerámicas pintadas que Álvarez Delgado pone en relación con el asentamiento bereber. La cronología de ambos grupos entraría dentro de la novena centuria. Caballero Zoreda las engloba dentro de su "Grupo II", extendido desde el valle del Ebro al centro de la Península y Portugal, formado por cerámicas que continúan dentro de la tradición visigoda, caracterizadas, por un lado, por una retracción y empobrecimiento de las formas; y, por otro, por el decaimiento de la estampación como técnica decorativa, el mantenimiento de las incisiones y el incremento de los ejemplares pintados ${ }^{89}$.

Como resumen, nos encontramos ante una fase de ocupación mozárabe que duraría hasta el siglo IX y que modifica parte de la estructura visigoda del edificio, con una evidente pérdida de calidad constructiva. La producción cerámica de uso habitual mantiene las formas tradicionales tardorromanas y visigodas, notándose, sin embargo, nuevas tipologías y decoraciones en la vajilla de mesa. Es interesante constatar la destrucción violenta del edificio, atestiguada por los restos de un gran incendio y el abandono in situ de los alimentos almacenados. La fecha de la destrucción se fijaría en tomo a mediados de la novena centuria, gracias a este lote de cerámicas y a la aparición de

\footnotetext{
${ }^{88}$ Y. Álvarez Delgado, Cerámicas comunes, p.407-412 y "Cerámicas del siglo IX" p.l18121.

${ }^{89}$ L. CABALlero ZoREDA, Pervivencias, p.128. La aparición de cerámicas pintadas no es habjtual en este periodo, aunque tampoco deja de ser algo extraño. En la misma Cuenca se conocen los ejemplares de La Dehesa de la Casa y, quizás, los de Villar de la Encina: M. LÓpEz ReQuena y R. Barroso Cabrera, La necrópolis de la Dehesa de la Casa, p.45, lám. 20. Fuera de Cuenca, los publicados por J. PÉrez VlzlanUeva, A. Tovar y J. Suplot, "La necrópolis visigoda de Piña de Esgueva", BVallad II (1933-34) p.407, fig.2; L. CABALLERO ZOREDA, Alconétar en la vía romnna de la Plata. EAE 70 (1970) p.29-30 y La necrópolis tardorromana de Fuentespreadas (Zamora). Un asentamiento en el valle del Duero. EAE 80 (1974) p.169-174; L. Caballero Zotedn, y Th. Ulbert, La basílica paleocristiana de Casa Herrera en las cercanías đe Mérida (Badajoz). EAE 89 (1975) fig.45, lám.XXXVI,c; L. CABALLERO ZOREDA, "Cerámicas de 'época visigoda y postvisigoda' de las provincias de Cáceres, Madrid y Segovia." BolArqMed 3 (1989) fig. 12,15; R. IZQUIERDo BENITO, "Cerámica de necrópolis de época visigoda del M.A.N." RArchBiblMtıs LXXX, n⿳3 (jul.- sept. 1977) p.602, fig.7,1; p.606, fig. 11,1; p.608, figs.13,1-2 y "Ensayo de una sistematización tipológica de la cerámica de necrópolis de época visigoda." RArchBiblMus LXXX, n 4 (oct.- dic. 1977) p.842-843.
} 
un dirham de plata, lo que concuerda bien con la fecha de huida del obispo Sebastián ${ }^{90}$.

\section{El "eremitorio" y la necrópolis aneja}

Fue ésta la primera zona excavada del área medieval. La primera campaña, dirigida por $D^{\mathbf{a}}$ Manuela Barthelemy en 1973, consistió en la excavación de veintidós sepulturas (señaladas en el plano con numeración arábiga). Una campaña posterior, dirigida diez años después por D. Carlos Moncó, se ocupó de continuar la excavación de esta misma necrópolis y del "eremitorio".

El Hlamado "eremitorio" consta de una nave exterior rectangular y una cámara circular abovedada excavada en la roca arenisca. Está orientado perfectamente en dirección norte-sur, encontrándose su cámara interior debajo de la parte occidental de la necrópolis.

A la primera nave se accede mediante dos peldaños tallados parcialmente en la roca. En su ángulo noroeste se talló un agujero de planta circular que se ha venido interpretando como silo. En las paredes este y oeste se aprecian huellas para sujetar la techumbre de lo que seguramente fuera un entramado de materiales perecederos o una primitiva construcción, así como numerosas oquedades, que interpretamos como huecos para colocar candiles, algunos muy deteriorados por efecto de la erosión pluvial. Desde esta nave rectangular, y a través de un vano, se accede a la cámara abovedada. El vano conserva dos rebajes en la parte superior de las jambas para apoyar un madero que haría las veces de dintel. Moncó ve en la jamba izquierda, a media altura, otro rebaje donde iría colocado el sistema de cierre de una puerta que separaría ambos ambientes. En cualquier caso, la cronología de esta separación no deja de ser dudosa, ya que la cueva fue utilizada posteriormente como chozo de pastor ${ }^{91}$.

El acceso a la cámara circular se realizaría a través de dos escalones tallados en la roca. El interior estaría, en principio, totalmente cubierto por una bóveda tallada en la arenisca, hoy día hundida a media altura de la sepultura XXVII, sin que podamos saber si el hundimiento fue debido por efecto de la

${ }^{90}$ El dirham lleva en el anverso la habitual profesión de fe islámica con leyenda de ceca (alAndalus) y fecha en los márgenes, esta última incompletn; en el reverso, leyendas religiosas en el centro y los márgenes. Cronología: 252-262H./866-876 d.C.; Y. Álvarez Delgado, Cerámicas comunes, p.409.

${ }^{1 !}$ Serf́a necessrio un trabajo de campo más intensivo -que nosotros, por desgracia, no pudimos realizar-para catalogar este tipo de construcciones rupestres, puesto que son muy numerosas en toda la zona de la Alcarrin conquense. En las cercanías de Huete tenemos conocimiento, gracias al testimonio de algunos vecinos del lugar recogidos en tos expedientes del Museo Provincial de Cuenca, de la existencia de construcciones y grabados de este tipo. 
construcción de ésta o, como parece más probable, tras el acondicionamiento del lugar como chozo.

En el interior de esta cámara, en su ángulo derecho, se encontró una sepultura tallada en la roca muy destruida por sus laterales, aunque todavía se puede constatar la existencia de un rebaje para tapa. A la izquierda de la entrada, se observa otro hueco tallado en parte en la roca y en parte natural, que fue interpretado como tumba, pero que más bien parece una huella natural del terreno. Ésta es una construcción rudimentaria de piedras asentadas mediante una lechada de cal y arena.

Sobre la pared se encuentran grabadas numerosas cruces y símbolos religiosos, a veces siguiendo el método de unir puntos que se aprecia en alguna inscripción de la provincia ${ }^{92}$. En general, se trata de cruces de calvario, con brazos rematados en triángulos o unidas por su base. Entre ellas destaca una situada axialmente, frente a la entrada, y una inscripción que reza FAH, situada justamente encima de la sepultura, y que encuentra su paralelo más cercano en la inscripción de la pileta de Tarragona del Museo Sefardí, cuyo significado exacto se desconoce, aunque en cualquier caso haya que vincularlo al contexto funerario en que aparecieron ambas ${ }^{93}$.

Un detalle que llama mucho la atención al estudioso es el gran número de pequeños agujeros taladrados que se encuentran por toda la cámara. Moncó creía que su funcionalidad era la de introducir palos que sujetaran maderas, con una función de altarcillos o alacenas ${ }^{94}$. Sin embargo, dada su profusión, es más probable que sirvieran para colgar candiles o velas para el culto ${ }^{95}$. En

\footnotetext{
${ }^{92}$ Por ejemplo, en una inscripción procedente de Villaescusa de Haro con leyenda +EBENTIVS. A. Rodriguez COlmenero, "Cleenca romana. Contribución al estudio epigráfico." Luckentum I (1982) p.226, lím. IX, l, calificada como paleocristiana o visigoda; J.M. MiLlÁN MARTíneZ (ed.). Compendio Histórico de Villaescusa de Haro. Villaescusa de Haro (Cuenca), 1984, p.92. El método de ejecución está muy generalizado en la época.

${ }^{93}$ F. CANTERA BURGOS, "¿Nueva inscripeión trilingie tarraconense?" Sefarad 15 (1955) p. 151156; H. SCHLUNK u. TH. HAUSCHILD, Die Denkmäler der frühchristichen tnd westgotischen Zeit. Hispania Antiqua. Mainz am Rhein, 1978, p.165-166, lám. 60b, dan la lectura $P A H$ y la fechan entre los siglos V-VI, con ciertas dudas; R. Barroso Cabrera y 3. Morin DE PABlos, El Arbol de la Vida. Un estudio de iconografía visigoda: San Pedro de la Nave y Quintanilla de las Viñas. Madrid, 1993, p.24-25.

${ }_{94}$ C. MONCÓ GARCía, El eremitorio y la necrópolis, p.248.

15. J. GonzÁlez EChegaray et al. "Las iglesias rupestres de Arroyuelos y Las Presillas." CentEstMont (1962) p.12. La ausencia de mobiliario litúrgico y la decoración de estos espacios hacen que en la actualidad presenten un aspecto de sobriedad que no se corresponde con la realidad, si bien nunca debieron ser obras suntuosas: L. A. MONREAL JIMENO, Eremitorios rupestres aftonedievales (el alto valle del Ebro). Bilbao, 1981, p.19, nt.8.
} 
cualquier caso, estos "condenados agujeros", que tanto desconcertaron a Íñiguez Almech, son habituales en las iglesias rupestres de la época ${ }^{96}$.

En el exterior del eremitorio se encuentra el grupo más numeroso de grabados. A excepción de uno de ellos, colocado al lado de una de las sepulturas y hoy día perdido, están tallados en una de las paredes del roquedo que dan al sureste, en la pared opuesta a la oriental del exterior del eremitorio. Entre los grabados destacan la gran cruz latina del centro del panel, un candelabro de siete brazos coronado por una cruz triunfante y una cruz de triple travesaño. Antiguamente era también apreciable una gran cruz de Calvario que ocupaba la parte inferior derecha del panel. Estos grabados son idénticos en cuanto a realización a los que aparecen en la parte inferior de la cámara interior, diferenciándose de los restantes por ser de trazos continuos, no mediante la unión de puntos.

El candelabro de siete brazos fue interpretado por Osuna y posteriormente por Moncó como un testimonio de criptojudaismo dentro del ambiente de persecución que sufre esta comunidad en el siglo VII ${ }^{97}$. En nuestra opinión, por el contrario, sólo indirectamente estaría relacionado con la religión hebrea: en realidad, su aparición se debe a la comunidad de fuentes entre cristianos y judios. En este sentido, la menorah no resulta privativa del mundo hebreo, sino que la encontramos representada en el ámbito católico con ejemplos muy significativos, entre otros, en la ventana del pórtico de la iglesia de San Pedro de la Nave. Su aparición estaría, pues, íntimamente relacionada con el éxito del Apocalipsis en la segunda mitad del siglo VII y, por tanto, con el sentido que le da el evangelista: el de los siete espíritus que están delante del trono de Dios y que simbolizan tanto a los siete dones del Espíritu Santo, como a los arcángeles que custodian el Reino (Apoc. $\mathrm{V}, 5 ; \mathrm{VIII,2ss})^{98}$.

Este panel meridional se hallaría protegido de la intemperie por una techumbre de madera, como lo evidencian las huellas de poste de la parte superior y la supuesta tumba 1 , que no es más que un rebaje para encajar una viga que termina, hacia la parte que da al eremitorio, en un pie derecho.

Asociada al eremitorio se encuentra la necrópolis, que se extiende alrededor del mismo en un nivel superior. Son, en total, unas 51 sepulturas (aunque

\footnotetext{
${ }^{96}$ F. ÍÑIGUEZ ALMECH, "Algunos problemas", p.48 y 62, supone que sirvieron para colocar palos que soportaran algún objeto indeterminado.

${ }_{97}$ M. OSUNA Ruz, "Las relaciones judeo-cristianas", p.152-!53; C. MonCó GaRCĺA, El eremitorio y la necrópolis, p.256.

98 R. Barroso Cabrera y 3. Morin de Pablos, El Árbol de la Vida. p.24-27, donde se citan ejemplos. Sobre el éxito del Apocalipsis véanse además: H. SCHLUNK, "Observaciones en torno al problema de la miniatura visigoda." ArchEspArt 71, t.XVIII (1945) p.260ss; J. M. LACARRA, La Península Ibérica del siglo VII al X, p.24l, y la obra citada en primer término, p. 123ss.
} 
nosotros no consideremos como tales un número significativo de ellas, que aparecen en el plano rayadas). Se trata de sepulturas excavadas en la roca arenisca, situadas alrededor del eremitorio, más concretamente de la bóveda, cuyo perímetro incluso aparece señalado en la roca con una línea. La mayoría de las tumbas, no obstante, se sitúan a ambos lados del eremitorio, siguiendo la línea del frente del roquedo por razones obvias de espacio.

Es interesante constatar la existencia de huellas de poste y de algunos rebajes cúbicos tallados en la roca (p.e. en la zona de las sepulturas XIII-XIV y XXIII-XXVI, y en otras con menos precisión) que dan la sensación de un escalonamiento artificial del roquedo. Este hecho parece indicar la existencia de construcciones semirrupestres en el lugar que antes se interpretara como cantera y al lado del eremitorio ${ }^{99}$.

Se documentaron además reutilizaciones de tumbas e, incluso, el uso constatado de alguna de ellas como osario. Asimismo, durante la excavación, se encontraron algunos restos de elementos de adorno personal (cuentas de pasta vítrea, pendientes, pulseras, anillos, etc.) y dos vasijas en sendas sepulturas. La cronología de estos hallazgos es otro de los puntos polémicos de este estudio pues, mientras que para Carlos Moncó permiten establecer dos fases distintas en la utilización del área como necrópolis, divididas por la construcción y uso del eremitorio ${ }^{100}$, nosotros creemos, por el contrario, que los hallazgos no permiten establecer más que una fase de cronología plenamente visigoda, entre los siglos VI-VII. En realidad, las vasijas encontradas en las tumbas XVIII y XXIX pueden encuadrarse perfectamente dentro de esta última centuria, ya que este tipo de cerámica mantiene durante mucho tiempo la tradición tardorromana, incluso para fechas tan tardías como el siglo IX, como puso de manifiesto el estudio de Yasmina Álvarez ${ }^{101}$. De esta forma, los restos cerámicos no entrarían en contradicción con el resto de los elementos de ajuar encontrados en la necrópolis (cuentas de collar de vidrio y ámbar, pendientes de bucle, pulsera de bronce, etc.) que el propio autor no duda en fechar hacia los siglos VI-VII, y que cuentan con abundantes paralelos en la zona ${ }^{102}$. El arcaismo de estas piezas cerámicas con respecto a las producciones halladas en otras necrópolis visigodas de Cuenca se puede explicar por la vinculación a

\footnotetext{
99 Construcciones de fábrica o en madera debieron ser habituales a buena parte de los eremitorios altomedievales: L. A. MONREAL JIMENO, Eremitorios rupestres, p. $18-19$.

${ }^{300}$ C. Moncó Garcla, El eremitorio y la necrópolis, y "El eremitorio de la necrópolis". Anteriormente, M. OSUNA Rutz, "Excavaciones arqueológicas en Ercávica. Castro de Santaver, Cañaveruelas (Cuenca). Agosto, 1973." NAH 5 (1977) p.26, la habia fechado en los siglos XII-XIII.

101 Y. Álvarez Delgado, Cerámicas comunes, p.411.

102 C. MONCó Garcia, La necrópolis y el eremitorio, p,253-255, foto 6; M. Almagro BasCH, La necrópolis hispano-visigoda de Segóbriga, Saelices (Cuenca). EAE 84 (1975) sepultura 60, $\mathrm{n}^{\circ} 1$, fig.16, y en la tumba VIII de la necrópolis de Belmontejo (Museo de Cuenca, $\mathrm{n}^{\circ}$ 80/2/34-35).
} 
un centro urbano de cierta entidad y, por consiguiente, más apegado a la tradición alfarera anterior.

Tampoco son excepcionales las piezas de vidrio semejantes a otras encontradas en diferentes necrópolis hispanovisigodas ${ }^{103}$. No es necesario remarcar, una vez más, que el cambio de poder político no supone una transformación radical en las realizaciones materiales; más bien al contrario, todo apunta a una continuidad con la tradición hispanorromana y una evolución a partir de ella, siguiendo los influjos mediterráneos. A todo ello hay que sumar además un dato conocido por excavaciones más recientes: la existencia de una necrópolis en el foro de la ciudad romana, fechable no antes del siglo $\mathrm{V}$.

Realmente, la teoría de Moncó es ciertamente complicada y sorprende por la variación de uso que supone para el área: primero se instala una necrópolis tardorromana que, después de abandonarse, se expolia; se realiza entonces una cantera (en un momento en que no se constata ninguna actividad constructiva en la ciudad, que posiblemente cuente solo con un asentamiento en la ladera sur); se sitúa después una comunidad eremítica junto al antiguo cementerio (!), que luego se traslada al monasterio, instalándose otra necrópolis en el mismo lugar. Todo esto en el plazo poco más o menos de un siglo.

\section{LAS NECRÓPOLIS}

Además de la necrópolis del eremitorio, se conocen otras dos más áreas cementeriales más: una de época hispanovisigoda, ubicada en el valle de la Isabela, y otra anterior situada en el foro de la antigua ciudad romana.

\section{La necrópolis de La Rinconada}

La necrópolis de La Rinconada fue excavada con carácter de urgencia por D. Carlos Moncó en 1982, aprovechando el bajo nivel del pantano de Buendía. Se trata de una necrópolis de, al menos, 13 tumbas de lajas orientadas

${ }^{103}$ Por ejemplo, en la necrópolis sevillana de El Tamargutillo: C. FERnández ChiCarro, "Adquisiciones del Museo de Sevilla." MMAP IX (1948) p.11 I, o en las granadinas de Las Delicias (siglo VI) y Zafartaya: M. RAMOS LizARRA et al. "Necrópolis altomedievales en Zafartaya, Granada." Revarqueo 78 (1987) p.57, e I. TORO MOYano y M. Ramos LizarRA, Las necrópolis de Las Delicias y el Almendral. Dos necrópolis visigodas en el Llano de Zafarraya (Granada). II CAME. Madrid, 1987, p.390-392. A pesar de que existe una decadencia evidente en la producción de vidrio, se conocen varios ejemplares de época visigoda, algunos -como las patenas- de clara signifícación religiosa: J. FerRANDIS, Artes decorativas visigodas, en HistEspMenPid vol.III. Madtid, 1940, p.716719.

De Hispania Visigoda

Hispania Sacra 48 (1996) 
este-oeste y situadas a los pies del espolón nororiental del cerro. La necrópolis se encontraba bastante afectada por la acción erosiva de las aguas del pantano. Está fechada en el siglo VII gracias a un broche liriforme aparecido en una de las sepulturas, lo que concuerda bien con la tipología de los enterramientos.

La localización de esta necrópolis parece probar la hipótesis de una bajada al llano de la población, estableciéndose en diferentes núcleos diseminados a lo largo del valle del Guadiela y, tal vez, con un núcleo principal en la zona de la Isabela aprovechando los baños termales y la proximidad a la vía hacia $S e$ gontia y Recópolis. Este poblamiento disperso es el que parecen reflejar las fuentes y la toponimia de época islámica ${ }^{10+} \mathrm{y}$, sin duda, favorecería la instalación de la comunidad de eremitas: una característica de las comunidades monásticas es su situación en los suburbios de ciudades en franco proceso de decadencia ${ }^{105}$.

\section{La necrópolis del Foro}

La segunda de las necrópolis a que hacemos referencia se excavó durante los trabajos efectuados por nosotros mismos en el foro romano en los años 1991-92. Se documentaron entonces siete sepulturas orientadas este-oeste, a excepción de una de ellas, en realidad un cenotafio, que iba orientado en dirección norte-sur. No se encontraron restos de ajuar ni depósito ritual en ninguna de las tumbas. El ritual de enterramiento era el propio de este tipo de sepulturas, con inhumación de cadáveres depositados en decubito supino.

La necrópolis viene a situarse en esta zona porque indudablemente continuaba manteniendo cierto carácter sagrado, más aún si, como pensamos, ésta se sitúa justo encima de las subestructuras de un templo capitolino. Algo similar a lo que conocemos de Pollentia ${ }^{106}$ y a lo que se podría suponer, con razonable fundamento, para la vecina Valeria.

La decadencia como núcleo urbano que denota esta necrópolis puede rastrearse ya desde la segunda mitad del siglo IV, dada la total ausencia de sigillatas tardías en el yacimiento. La ubicación de una necrópolis en pleno foro no pudo realizarse, de cualquier modo, antes de la ley teodosiana que ordena el mantenimiento de templos y monumentos, y, probablemente, no sea sino posterior a aquella otra ley que ordena la destrucción de los templos paganos y

\footnotetext{
114 L. TORRES BaLBAs, Ciudades yemas hispanomusulmanas. Madrid, 1957, p.27; Y. ÁlvareZ DELGADO, Cerámicas comunes, p.405-406.

${ }^{105}$ F. ÍN̂́rGUEZ ALMECH, "Algunos problemas", p.2I \$s.

106 A. ARribas y M. TARRADELL, El Foro de Pollentia. Noticias de las primeras investigaciones, en Los Foros romanos de las provincias occideniales. Madrid, 1987, p.135-136.
} 
su purificación mediante el signo de la $\mathrm{cruz}^{107}$. Una fecha posterior al siglo $\mathrm{V}$ supondría la existencia de un lapsus cronológico demasiado amplio, que no parece corresponderse con la evolución urbana más probable. En este sentido, la ausencia de un núcleo urbano en las cercanías del yacimiento diferencia el caso de los enterramientos del foro arcavicense de los de Valeria, donde los enterramientos se han mantenido hasta el presente siglo. Para Arcávica, y a pesar de que haya que suponer una lógica destrucción de un buen número de sepulturas, parece observarse la existencia de una población residual en época tardorromana, de escasa entidad demográfica y muy apegada a tradiciones religiosas anteriores. Junto a esto, la necrópolis del foro viene a certificar la desaparición definitiva de la organización municipal romana y su presumible sustitución por el patronato episcopal.

\section{El Pocillo}

Tradicionalmente se viene denominando así a un manantial de agua que ha sido aprovechado para la realización de una fuente. Esta fuente se ha construido mediante tres muros de sillares romanos reutilizados, colocados a hueso y calzados con tejas; una técnica que tiene sus precedentes en algunas construcciones paleocristianas, como es el caso de la cripta de las Vegas de Puebla Nueva (Toledo) ${ }^{108}$ y que veŕamos antes en el vecino monasterio. La fuente presenta la singularidad de tener el acceso escalonado hasta el centro del manantial. Parte de esta escalinata quedaba sumergida, apoyándose en grandes rocas sin labrar que le servían de basamento.

En el alzado de la pared norte de esta fuente se encuentra grabada una cruz de Calvario similar a las desaparecidas del interior del eremitorio, aunque de trazado más perfecto.

La interpretación de esta fuente es compleja. Realmente, esta obra se adapta a la disposición requerida para los baptisterios ${ }^{\mathrm{j} 09} \mathrm{y}$, es posible incluso,

\footnotetext{
107 Codex Theodosianus, 16.10.5 (a.399) y 16.10.25 (a.435): 1. ARCE, El último siglo de la España romana: 284-409. Madrid, 1982, p.137-138. La necrópolis del foro de Pollentia sería algo anterior a estas fechas de tener en cuenta la datación de las monedas encontradas, pero dicha datación es muy dudosa no sólo porque supone llevar los enterramientos a fechas muy tempranas (la sepultura 77 se fecharía entonces hacia $276-282$, y la 36 y 38 , durante Constantinol, sino por el propio testimonio de sus excavadores que plantean la posibilidad de que las pequeñas monedas se encontraran con la tierra que sirvió de relleno a las fosas: A. Arribas y M. TARRADELl, El Foro de Pollentia, p.136.

INB TH. HAUSCHILD, Técnicas y maneras de construir, p.75-76.

${ }^{109}$ P. DE PALOL, Arqueología cristiana de la España romana (siglos V-VI). Madrid, 1967, p.147-175.
}

De Hispania Visigoda

Hispania Sacra 48 (1996) 
que el número de escalones tallados fuera efectivamente de tres, tal como dispone San Isidoro ${ }^{110}$, aunque esto sea más dudoso. La situación del Pocillo permite el acceso del neófito desde oriente ${ }^{111}$, y también el agua de manantial se presta a las necesidades litúrgicas del caso ${ }^{i r z}$; la presencia de la cruz coronando la construcción es además muy significativa por cuanto parece expresar la santificación del lugar.

Una posible objeción a esta interpretación es que el Pocillo se halla distanciado un tanto de la iglesia. Sin embargo, esto no sería un obstáculo definitivo para suponerlo una edificación bautismal: se conocen, al menos, cinco casos peninsulares semejantes, aparte de que la distancia no es excesiva si se tiene en cuenta el gusto por las procesiones de la liturgia de la época. Así podría verse, por ejemplo, en el grabado de la pizarra de Huerta (Salamanca), en el que dos ciervos que salen de una piscina bautismal se dirigen hacia un edificio que cabe interpretar como iglesia ${ }^{13}$.

Aunque la separación entre iglesia y'baptisterio parece típica deI mundo oriental, y bien pudo venir con la comunidad norteafricana, es más probable que en el caso de Arcávica esta disposición venga determinada por la propia fisonomía del terreno y por la presencia de un manantial natural en el lugar. Hay que tener en cuenta, además, que en el norte de Africa lo usual es que los baptisterios se encuentren adosados a los edificios ${ }^{114}$. Existe, no obstante, un paralelo norteafricano bastante cercano en cuanto a tipología y datación en el baptisterio de Junca, en Túnez ${ }^{115}$.

Las piscinas bautismales rectangulares constan habitualmente de una doble escalinata simétrica con objeto de facilitar el acceso al agua sagrada y la posterior salida por el lado contrario. Aquí, sin embargo, sólo encontramos un único acceso debido, principalmente, a la topografía del lugar y a la propia morfología de la fuente. No obstante, esto tampoco sería un obstáculo grave,

\footnotetext{
"10 Isid. Hisp. Etymologianm, XV,4,9-10 (ed. J. OROZ RETA y M.A. MarCos CASQuERo, p.238-239).

III P. DE PALOL, Arqueología cristiana, p. 148.

112 J. FERNÁNDEZ ALONSO, La cura pastoral, p. 287.

I13 M. SANTONJA y M. MORENO, "Tres pizartas con dibujos de época vísigoda en la provincia de Salamanca." Zephyrus 44-45 (1991-1992) p.472-475, interpretan la representación como parte de un mismo edificio que constaría de baptisterio e iglesin. En nuestra opinión, parece tratarse de un mismo conjunto compuesto por dos edificios diferentes para cuyo caso existirían numerosos paralelos.

II4 P. DE PALOL, Arqueología cristiana, p.150.

Iis Se fecha también en la sexta centuria: G. L. FEUlLLE, "Le Baptistere de Junca (Macomades, Minores) ${ }^{1+}$, CaArch 3 (1948) p.75-81; CH. PICARD, L'archéologie chrétienne en Afrique (1938-1953). Actes du Se. Congrés international d'archéologie chrétienne. Aix-en-Provence (13-19 sept. 1954). Cite du Vatican-Paris, 1957, p.54; A. KHATCHATRIAN, Origine et iypologic des baptistéres paléochrêtiennes. Mulhouse: Centre de Culure Chretienne, 1982, p.11 y 42, y Les baptistéress paléochrétiennes. Plans, notices et biblingraphie. Paris, 1962, p.36-37 y 96.
} 
pues se repite en el baptisterio de Junca ${ }^{116}$. Este caso ilustra bien la remota posibilidad de que el llamado "silo" del eremitorio estuviera en relación con el bautismo de infantes. Téngase en cuenta que en el periodo visigodo se conocieron ya pilas pequeñas (denominadas "vasos"), seguramente destinadas a este fin. De hecho, es precisamente esta época cuando cambia la costumbre de bautizar adultos por la de impartir el sacramento ya desde edad infantil ${ }^{117}$. Ejemplos similares se pueden ver, de forma más rudimentaria si cabe, en iglesias rupestres de Álava y la montaña burgalesa ${ }^{18}$. Lo más probable es, sin embargo, que dicho "silo" no esté relacionado con el eremitorio, sino con la reutilización del mismo como chozo de pastor.

En cualquier caso, la escalinata, el grabado de la cruz de Calvario y la cercanía a la iglesia podrían avalar la hipótesis de que el Pocillo sea, en realidad, un baptisterio singular ligado a ceremonias litúrgicas de tipo procesional.

\section{CONCLUSIONES}

Una cuidadosa observación de la colocación de las sepulturas excavadas en la segunda campaña permite ver como éstas se han colocado ordenadamente alrededor de la bóveda del eremitorio. Incluso, como ya se ha comentado, se ha llegado a marcar el área de la cámara circular en la parte superior del roquedo mediante una gruesa incisión. Esto hace pensar que no se trata de un hecho casual, más aún cuando las tumbas no parecen guardar la orientación típica este-oeste, ni una disposición en línea. Incisiones como ésta que marca los límites de la cámara inferior se encuentran, asimismo, relacionando sepulturas próximas, seguramente siguiendo criterios familiares, como sucede en la necrópolis altomedieval de San Salvador de Valdediós fechada en tiempos de Alfonso III ${ }^{119}$. Esto parece probar que la ordenación del cementerio obedeció a razones preconcebidas, bien en relación con la cripta, bien entre las propias fosas entre sí.

${ }^{116}$ TH. ULBERT, Frïhchristiche Basiliken mit Doppelapsiden auf der Iberischen Halbinsel. BerIin, 1978 , p. 157 ; C. GODOY FERNÁNDEZ, Reflexiones sobre la funcionalidad litútgica de pequeñas pilas junto a piscinas mayores en los baptistetios cristianos hispánicos. I CAME. Huesca, 1985 (Zaragoza, 1986) p.130.

117 J. Pijuán, La liturgia bautismal en la España ronano-visigoda. Toledo, 1981, p.67.

${ }^{\prime \prime}$ F. Ífiguez Almech, "Algunos problemas", p.49; J. GONZÁlEZ ECHEGARAY el al. "Las iglesias rupestres", p.16-19.

${ }^{119}$ A. MARTINEZ VILLA, Novedades arqueológicas en San Salvador de Valdediós (Asturias). Reunión sobre novedades de arqueología y arquitectura alo-medieval en España. Madrid, CSIC, 23 y 24 de Abril de 1990.

De Hispania Visigoda Hispania Sacra 48 (1996) 
No cabe duda de que la colocación de las sepulturas guarda relación con la tumba colocada en el interior del eremitorio, que es además la única que se ha significado. En efecto, tanto la inscripción FAH como el signo angular asociado a ella se colocaron justo encima de esta tumba con el deseo evidente de resaltarla sobre las demás. Ambos grabados, además, están realizados con mayor precisión técnica, con un buril de sección triangular, a imitación de las letras capitales romanas y siguiendo la técnica de unir puntos, que parece ser la habitual de los signos grabados por la comunidad monástica. Desde esta óptica, pues, parece claro que las sepulturas del exterior se organizaron en una típica disposición ad sanctos ${ }^{120}$. Idéntica creencia en el carácter beatífico del difunto que ocupaba la tumba interior debieron tener los numerosos grabados de carácter popular que se encontraban en la entrada a la cámara y en la pared $^{121}$.

Es el momento, pues, de volver sobre la narración de Ildefonso, aquélla que refiere la veneración de Donato después de su muerte:

"Hic et in praesenti luce subsistens et in cripta sepulchri quiescens, signis quibusdam proditur effulgere salutis, unde et monumentum eius honorabiliter colere perhibentur incolae regionis."

En otras palabras, el abad del Servitano fue enterrado en una cripta sepulcral y su memoria era venerada por los habitantes de la región por ciertos indicios de carácter milagroso ${ }^{122}$. Como es fácil comprobar, la comparación del texto de Ildefonso con los datos que han proporcionado los distintos trabajos arqueológicos permite realizar una descripción bastante verosímil de como debieron sucederse los acontecimientos históricos.

En principio, tendríamos la llegada de Donato y sus setenta monjes y la fundación del monasterio Servitano en tierras arcavicenses antes del año 571, en que aparece citado por primera vez en la Crónica del Biclarense ${ }^{123}$. La noticia de Ildefonso acerca de que anteriormente había sido discípulo de un ermitaño explica que mientras durase la construcción del monasterio en el Vallejo del Obispo la comunidad cenobítica se estableciera alrededor de una iglesia rupestre (el llamado "eremitorio"), en celdas semiexcavadas (laurae) en la roca o aprovechando ésta en parte, como parece apreciarse en las huellas para vigas encontradas a ambos lados de la cripta y por encima de ella. El carácter eclesial de la construcción más representativa se puede colegir de algunos

\footnotetext{
I2U Sobre este tema, Y. DUVAL, Auprès des saints, especialmente p.52-57.

${ }^{121}$ En cierto modo, expresiones de un culto popular equivalentes a fólmulas más desarrolladas en otros ejemplos citados por Y. DuvaL, Auprès des saints, p. I34-I36. p.28.

J. PEREZ DE URBEL, Los monjes españoles. t.[1, p.2I; R. Puertas Tricas, Iglesias hispánicas.

12.3 Así lo argumenta con razón el padre Florez: ES, t.VIII, p.61.
} 
grabados, especialmente de la cruz con aspa en la base que se encuentra situada en el lugar preferente de la cámara interior, al fondo de la misma, justo frente a la entrada.

Es, pues, muy posible que el monasterio primigenio fuera, en realidad, una serie de celdas semirrupestres - a modo de las lauras de los Padres del Desierto- en torno a un oratorio común que ocuparía el centro de la vida religiosa ${ }^{124}$; pues lo cierto es que, como recuerda Íniguez Almech, el monasterio se forma con el cónclave, es decir, el "locus inclusus vel munitur, sive domus quae multis clauditur cellis", y es allí donde tiene lugar la collatio o reunión de los monjes ${ }^{125}$.

De este carácter ascético que se entrevé en las fuentes y la arqueología se puede deducir que el nombre del monasterio derive del término servi Dei y no de un hipotético fundador o posesor, como supusieron ya algunos autores y recoge Flórez; un nombre muy indicado para una comunidad monástica de origen eremita ${ }^{126}$. De hecho, el término aparece citado anteriormente como nombre propio entre algunos obispos visigodos ${ }^{127}$, a la vez que se trata de un apelativo harto frecuente en la literatura hispanovisigoda para denominar a los monjes ${ }^{128}$. Hay que señalar, además para esta época, el uso de famulus/a Dei o famulus/a Christi como expresión con idéntico significado ${ }^{129}$; aunque es po-

\footnotetext{
974.

${ }^{124}$ C. C. Walters, Monastic Archeology in Egypt. Modern Egyptology Series. Warminster,

${ }^{125}$ F. Í́NIGUEZ ALMECH, "Algunos problemas", p.27-28. Un ejemplo parecido es el de la iglesia de San Miguel de las Presillas (Burgos): J. GONZÁlez ECHEGARAY et al. "Las iglesias rupestres", p.15-19.

126 ES, t. VIII, p.59.

${ }^{127}$ L. A. Garcla Moreno, Prosopografía, n²66, p. 125 , obispo de Basti y $n^{\circ} 452$, p. 174 , obispo de Caliabria. Nombres como éstos o similares (Drmum Dei, Adeodatus), podrían haber sido adoptados después de abrazar el estado clerical, aunque no tiene que ser necesariamente así y pueden responder a una creciente cristianización de la onomástica: como es sabido, Adeodato se llamaba el hịjo de Agustín.

${ }^{128}$ Una fómula similar es utilizada asimismo por Alfonso Il, seguramente debido a la adopción de usos y costumbres monísticos por parte del monarca asturiano: H. SCHLUNK, El arte asturiano en torno al 800 . Actas del Simposio para el estudio de los códices del Contentario al Apocalipsis de Beato de Liébana, t.I **, Madrid, 1980, p.l42-145; I. G. BANGO TORviso, "L'Ordo Gotorum et sa survivance dans l'Espagne du Haut Moyen Age." Revue de l'Art 70 (1985) p.14-15 y nt.77 y Alta Edad Media. De la tradición hispanovisigoda al Románico. Madrid, 1989, p.34-38.

${ }^{129}$ Véanse los ejemplos citados por Ae. Hübner, Inscriptionum Hispaniae Christianarum Supplementum. Berlin, 1900 (ver Designationes Sanctorum et Piorum, en p. 149) y Dom F. CABROL- H. LECLERQ, Dictionnaire d'Archénlogie chrétienne et de Liturgie. Paris, 1922, p.481-498. En los casos que se han podjdo fechar con exactitud, las inscripciones cortesponden a la segunda mitad del siglo VI en adelante: I. VELȦZQUEZ SORIANO, Las pizarras visigodas: edición críticn y estudio. Antigüedad y Cristianismo, VI. Murcja, 1989, p.558. No obstante, la fórmula famultus Christi comienza a sustituir a la más genérica famulus Dei a partir del 450: J. N. HLllgarTH, Popular Religion, p.31. Véase también, H. SCHLUNK, El arte asturiano, p.142-143.
} 
sible que esta última fórmula no tenga relación con una vida regular, sino que se trate de una expresión de tipo popular. Dado el probable origen bizantino de la fórmula servus Dei, ésta pudo llegar al Norte de África en época muy temprana y, desde allí, arribar a la península con los monjes de Donato que serían, en última instancia, quienes la popularizarían por el país.

Una vez construido el monasterio, gracias a la gestión y apoyo de Minicea, y tras la muerte de Donato, el cuerpo del abad sería enterrado en el interior de la antigua iglesia ahora convertida en cripta sepulcral, en olor de santidad a tenor de lo que dicen Ias fuentes, tanto su biógrafo Ildefonso, como la mención del Biclarense. El mecenazgo de esta dama pone de relieve además el importante papel desempeñado por este tipo de damas de origen aristocrático en la difusión de la fe cristiana entre las capas populares del reino. La obra de Minicea es, en este sentido, equiparable al de un reducido número de nobles señoras cuyo testimonio ha quedado recogido en la epigrafía del momento. Así, por ejemplo, una inscripción de la época hace referencia a una cierta dama llamada Anduires que juntamente con su marido dispuso la edificación de una iglesia. Más notable aún es el caso de la condesa goda Gudiliuva, que hizo donaciones para la construcción de tres templos entre los años 594-610 ${ }^{130}$.

Alrededor de la sepultura del abad, gracias a la creencia extendida entre el pueblo del carácter milagroso de sus restos ${ }^{131}$, se iría extendiendo una necrópolis formada por los monjes y personas vinculadas al monasterio ${ }^{132}$. Testimonio de la devoción que el pueblo tributaba a su memoria son los grabados que se han tallado a los pies de la cripta y en varias partes del roquedo, siempre alrededor del sepulcro venerado.

El culto local a confesores aparece registrado en otros casos de época visigoda e, incluso, en tiempos anteriores, tanto entre los cristianos orientales como en Occidente ${ }^{13.3}$. Un ejemplo del periodo que nos ocupa, muy similar y que pudiera ser fundador asimismo de otro monasterio, el de Aquis en la Lusitania, sería el de Pimenio, ${ }^{134}$ monje sobre el que también existen indicios de

$130 \%$ J, VIVES GATELL, Inscripciones cristianas de la España ronana y visigoda. Barcelona, 1969, $n^{\circ} 505$ y 303 respectivamente; J. N. HILlgarTh, Popular Religion, p.21-22.

131 Para esto, véanse los trabajos de J. FONTAINE, "El De viris illustribus", p.80-82 y Y. DuvaL, Auprès des saints, p.176-179.

${ }^{132}$ Las razones de la asociación de tumbas a un enterramiento privilegiado se analizan en $Y$. DUVAL, Auprès des saints, p. $1-19$ y 203 ss.

${ }^{133}$ Existen multitud de ejemplos, a pesar de que esta práctica poputar era contraria a los principios teológicos cristianos: Y. DuVAL, Auprès des saints, passin. Además, la práctica de enterrar a los fundadores de primitivos asentamientos eremíticos en la celda o cueva que habín constituido su morada es habitual desde los orígenes del monaquismo, constituyéndose en puntos focales como santuario o martyrium: C. C. WALTERS, Monastic Archeologic, p.229-234.

${ }^{114}$ C. García Rodriguez, El culto a los santos, p. 346. 
veneración popular. Ciertamente, los enterramientos en el interior de iglesias están expresamente prohibidos por el canon 18 del I Concilio de Braga de $561^{135}$. Sin embargo, esta prohibición no se correspondía con la práctica real, dándose desde antiguo algunos testimonios en contra ${ }^{136}$ que tal vez influyeron en la aprobación de este canon. Algunos autores ven una prueba del incumplimiento de la disposición conciliar en la reiteración de las prohibiciones de sínodos posteriores; no obstante, lo cierto es que parece que en España se acató esta norma con cierto rigor a partir del siglo VII ${ }^{137}$.

De cualquier modo, en el caso del abad del Servitano una circunstancia facilitaba el enterramiento en la cripta: después de la construcción del monasterio la iglesia rupestre debió perder su primitiva función, seguramente para utilizarse como oratorio secundario o ermita. También hay que tener en cuenta el propio carácter eremítico de la iglesia y el hecho de que Donato fuera el fundador de la comunidad ${ }^{138}$, lo que le acerca a otros casos conocidos. Así, el enterramiento de Donato en el interior de la cueva recuerda extraordinariamente al de San Millán, muerto el 12 de noviembre de 574 y, por tanto, coetáneo al abad del Servitano. Después de su muerte, el cuerpo del evangelizador de los cántabros fue colocado en su celda monacal: "Corpus eitus... depositum est, ubi et manet in suo oratorio ${ }^{\prime 139}$.

Las mismas circunstancias se repiten nuevamente con San Frutos en el Duratón, cerca de Sepúlveda, en tierras segovianas ${ }^{140}$. Hay que subrayar, además, que ambos casos están en relación con cenobios semirrupestres similares al que estamos comentando. Otros ejemplos similares, aunque anónimos, se en-

13 J. Vives Gatell, Concillos, p.75; J. Fernández Alonso, La cura pastoral, p.583; 1. G. BANGo TORVISO, "El espacio para enterramientos", p.94.

1.36 J. FERNÁNDEZ ALONSO, La cura pastoral, p.583; F. Í́íIGUEZ ALMECH, "Algunos problemas", p.29; I. G. BANGO TORVISO, "El espacio para enterramientos", p.94-95 y nt.59. El caso tan cercano de Segóbriga es un ejemplo en cierto modo parangonable, por cuanto lo mús seguro es que la basílica exterior se construyera precisamente en el lugar ocupado por un núcleo funerario de importancia: $P$. de Palol Salellas, Arte y Arqueología, en HistEspMenPid. Jover Zamora, t.lll **t. España visigoda. Madrid, 1991, p.318. Posteriormente, en la basílica se habilitó un crucero para el enterramiento de personalidades, entre ellas tres obispos de la sede.

${ }^{137}$ Entre los que defienden el incumplimiento de la normativa: J. ORLANDIS TORRES, "Sobre la elección de sepultura en la España medieval." AnHistDer 20 (1950) p.5-49. Con argumentos más sólidos se muestra contrario a esta idea, 1. G. BANGo ToRviSo, "El espacio para enterramientos", p.93-106.

${ }^{138}$ C. C. WALTERS, Monastic Archeologic, p.229.

13: F. ÍNIGUEZ ALMECH, "Algunos problemas", p.28.

${ }^{140} \mathrm{M}^{\mathrm{s}}$ S. Martín Postigo, San Frutos del Duration, p.26-27; F. ÍNIGUEZ Almech, "Algunos problemas", p.61-62. De creer a la tradición, el santo murió hacia 715 .

De Hispania Visigoda

Hispania Sacra 48 (1996) 
cuentran en las ya citadas cuevas eremíticas de Álava y Burgos, de datación dudosa, pero encuadrables entre los siglos VII-IX ${ }^{141}$.

En cualquier caso, los ejemplos citados anteriormente y algunos otros señalados por Íñiguez Almech ${ }^{142}$ parecen probar que la prohibición bracarense no rezaba con este tipo de construcciones rupestres ni con las celdas monacales, restringiéndose a iglesias y basílicas.

Hacia el año 583 aparece ya Eutropio como sucesor de Donato en la dirección del Servitano. Años antes, en 578, siempre según la narración del Biclarense, Leovigildo había puesto en orden la totalidad de Hispania y decide entonces, como modo de reafirmación de su poder real y culminación de su obra política, la fundación de una ciudad en la Celtiberia llamada Recópolis en honor de su hijo Recaredo. La cercanía de esta nueva urbe regia a Arcávica y el importante foco cultural que debía constituir para la época el monasterio Servitano (no se olvide que Donato y sus monjes vienen con un importante cargamento de libros: "copiosisque librorum codicibus"143) hacen muy probable que Eutropio pasara a ser entonces el tutor del príncipe, el autor de su conversión a la fe católica, tal como intuyó Díaz y Díaz. Esto explicaría satisfactoriamente el destacadísimo papel que desempeñó el abad del Servitano en la organización del III Concilio de Toledo ${ }^{144}$ y en los planes de orden político que se advierten en su perdida correspondencia con Liciniano de Cartagena ${ }^{145}$. Nótese que en ambos casos la figura de Eutropio aparece significativamente ligada a la de Leandro de Sevilla en una suerte de vidas paralelas: tutor de Hermenegildo, organizador del sínodo de la conversión y, asimismo, con relación epistolar con Liciniano. Realmente, de no aceptarse esta interpretación resultaría un tanto extraño este protagonismo compartido con la figura más grande del episcopado hispano, incluso sobresaliendo a la altura de un obispo de la talla de Másona, metropolitano de Mérida, tan significado en la lucha

${ }^{141}$ Ibidem, p.44ss; J. LATXAGA, Istesias rupestres visigóticas en Álawa. La Camadocia del País Vasco o el complejo rupestre nás importante de Europa. Bilbao, 1976; A. AZKARATE GARAlOLAUN, Arqueología cristiana de la Antigüedad tardía en Alava, Guiptizcoa y Vizcaya. VitoriaGasteiz, 1988, p.14lss y mapa de distribución en p.I35.

${ }^{142}$ F. Í́̃iGUEZ ALMECH, "Algunos problemas", p.29, donde se citan los casos de un monje del monasterio de Cauliana y el de los obispos emeritenses Másona, Paulo y Fidel.

${ }^{143}$ E. SÁnCHEZ SAlor, "La cultura", p. 25-26; J. M. LACARRA, La Península lbérica, p.241-242.

${ }^{\text {id4 }}$ Nos remitimos de nuevo a este respecto a las palabras de elogio que le dedica el Biclarense, quien se refiere a la actuación de este abad en el Ill Concilio de Toledo en términos que no dejan lugar a dudas de su valía personal, llegando a brillar "quasi stella matuina in medio nebulae.": Ionn. Bicl. Chronica, 590,1; ed. J. Campos, p.97-98, 140 y 148; véase también lo đicho por J. PÉREZ DE URBEL, Los monjes es.joñoles, t.I p.203-205.

${ }^{145}$ Isid. Hisp. De vir. Illust. XLII y XLV (ES, t.V, p.445-447; C. CODOÑer Merino, Isidoro de Sevilla, XXXIl, p.152). Véase asimismo C. CODOÑER MERINO, Ildefonso de Toledo, p.50-52 y nt.129. 
contra el arrianismo como defensor de las reliquias de Santa Eulalia y godo de estirpe noble; por encima incluso del obispo Eufemio de Toledo que, inverosímilmente, no habría resultado elegido para la organización de un Concilio tan trascendental para los designios del Reino ${ }^{146}$.

No es imposible tampoco que la relación de la nueva ciudad regia con $\mathrm{Ar}$ cávica y del propio rey con el abad del Servitano expliquen la presencia del obispo Pedro en el sínodo reunido por Recaredo en Toledo el año 597, donde no aparecen, sin embargo, los otros dos obispos conquenses que sí habían tomado parte en el anterior ${ }^{147}$. Quizá los obispos arcavicenses anteriores al Sínodo de Gundemaro habían adoptado el papel director de la Iglesia en la provincia celtibérica. Eso explicaría satisfactoriamente el epíteto usado por los obispos arcavicenses y el hincapié que se hace en recordar que sólo existe una provincia (la Cartaginense, ahora con capital en Toledo). Se trata, en cualquier caso, de no crear nuevas entidades territoriales que pudieran hacer discutible el título capital adoptado por la، sede toledana.

Como premio a la labor desempeñada a lo largo del gobierno de Recaredo, y pensando quizá en este papel de transmisor de las ideas reales en busca de una solución pacífica al conflicto con los imperiales, Eutropio fue elegido obispo de la sede valenciana ${ }^{148}$. Es aquí donde habría que incluir la correspondencia mantenida entre el antiguo abad y el obispo de Cartagena, y el posterior envenenamiento de Liciniano en Constantinopla, donde no cabe duda que un obispo que mirase con buenos ojos la reintegración del territorio ocupado al monarca visigodo sería visto con cierto recelo.

A partir de la elección de Eutropio como obispo de Valencia, el Servitano deja de aparecer por completo en los testimonios escritos de la época, al tiempo que la ciudad de Recópolis, heredera del antiguo municipio romano de Ercávica, decaía lentamente. Con la llegada al trono de Recaredo, Toledo y los monasterios vinculados a la corte regia irían acaparando todo el favor del nuevo monarca. En este sentido, es muy posible que la mayor parte de los fondos del Servitano fuera trasladada a algún monasterio de la capital, en concreto al de Ágali, con el que Codoñer piensa que tuvo una relación directa.

El final de la comunidad mozárabe de Arcávica está atestiguado también por las fuentes y explica el nivel de incendio y destrucción que se observó

\footnotetext{
${ }^{446}$ Másona preside el Concílio de Toledo como obispo de mayor antigiedad y tras él, posiblemente por el rango y dignidad del Sínodo, Eufemio de Toledo y Leandro de Sevilla: J. VIVES GATELL, Concilios, p.136; J. PÉREZ DE URBEL, Los monjes españoles, t.l, p.275. La firma de Eutropio no aparece por ser abad.

147 J. VIVES GATELL, Concilios, p.157.

${ }_{148}$ M. C. DíaZ Y DíAZ, Introducción, p.21 nt.43; J. Orlandis, La Iglesia en la España visigótica, p.204.
}

De Hispania Visigoda

Hispania Sacra 48 ( 1996$)$ 
durante la excavación del edificio, así como el desalojo precipitado del mis$\mathrm{mo}^{149}$. Es el momento de la huida del obispo Sebastián hacia tierras asturianas, hecho sucedido durante el reinado de Ordoño I, a mediados del siglo IX ${ }^{150}$.

La fuga de las poblaciones mozárabes de al-Andalus hacia el norte cristiano es un claro indicio de su condición de minoría religiosa provocada por el aumento de las conversiones y la islamización de la población hispana. Con a ello aumentó también la intolerancia hacia la minoría cristiana. Con el final de la comunidad mozárabe, el recuerdo del abad Donato y del monasterio por él fundado se pierde entre las páginas del tiempo. A partir de este momento, Santaver entra ya dentro de la historia de la España musulmana, donde tendrá un destacado papel debido a su carácter fronterizo y a las continuas rebeliones bereberes que se suceden hasta el definitivo asentamiento del Califato ${ }^{151}$.

El punto final de esta historia lo pone la restauración del obispado de Arcávica, juntamente con el de Valeria, en la recién conquistada ciudad de Cuenca. La unificación de ambos obispados por Alfonso VIII pudo llevarse a cabo merced a una bula pontificia extendida por el papa Lucio III ${ }^{152}$.

14y Y. Ályarez Delgado, Cerámicas comunes, p.409 y 412.

1.5il F. FITA, "Sebastián, Obispo de Arcávica", p. 333-336.

${ }^{151}$ El tema ha sido estudiado por L. TORRES BALBÁS, Citudodes yermas, p.25-34.

${ }^{152}$ ES, t.VII, p.79; t.VIII, p.207. 


\section{Abreviaturas}

ActSalmant
AnEstMed
AnDepHistTeorArt
AnTol
ArchEspA
ArchEspArt
ArchPrehistlev
BAcHist
BMusMadr
BolArqMed
BVallad
CaArch
CAME
CentEstMont
CentEstPl
CentEstRom
CongHistCM
ConglntArchchrét
CuadtrabEscEspArq Roma
EAE
Estärhebr
Esthistagr
EtAug
HistEspMenPid
MAcHist
MM
MMAP
NAH
RArchBiblMus
RArqPalHisp
RevArqueo
RevPortHist
Settstudaltmed Spoleto.

Acta Salmanticensia. Salamanca.

Anuario de Estudios Medievales. Barcelona.

Anuario del Departamento de Historia y Teoría del Arte.

Anales Toledanos. Toledo.

Archivo Español de Arqueología.

Archivo Español de Arte.

Archivo de Prehistoria Levantino. Valencia.

Boletín de la Real Academia de la Historia.

Boletín del Museo Arqueológico Nacional.

Boletín de Arqueología Medieval.

Boletín del Seminario de Arte y Arqueología. Valladolid.

Cahiers Archéologiques. Paris.

Congreso de Arqueología Medieval Española.

Centro de Estudios Montañeses. Santander.

Centro de Estudios de la Plana. Castellón.

Centro de Estudios del Románico. Aguilar de Campóo (Palencia).

Congreso de Historia de Castilla-La Mancha. Toledo.

Congrés International d'archéologie chrétienne.

Cuadernos de trabajo de la Escuela Española de Arqueología de Roma. Roma-Madrid.

Excavaciones Arqueológicas en España.

Miscelánea de Estudios Árabes y Hebráicos. Granada.

Estudios de Historia Agraria. Barcelona.

Etudes Augustiniennes. Paris.

Historia de España dirigida por R. Menéndez Pidal.

Memorias de la Real Academia de la Historia.

Madrider Mitteilungen.

Memorias de los Museos Arqueológicos Provinciales.

Noticiario Arqueológico Hispánico.

Revista de Archivos, Bibliotecas y Museos.

Reunión de Arqueología Paleocristiana Hispánica.

Revista de Arqueología.

Revista Portuguesa de Historia. Coimbra.

Settimane di studi sull'alto Medioevo. Spoleto.

De Hispania Vișigodi Hispania Sacra 48 (1996) 

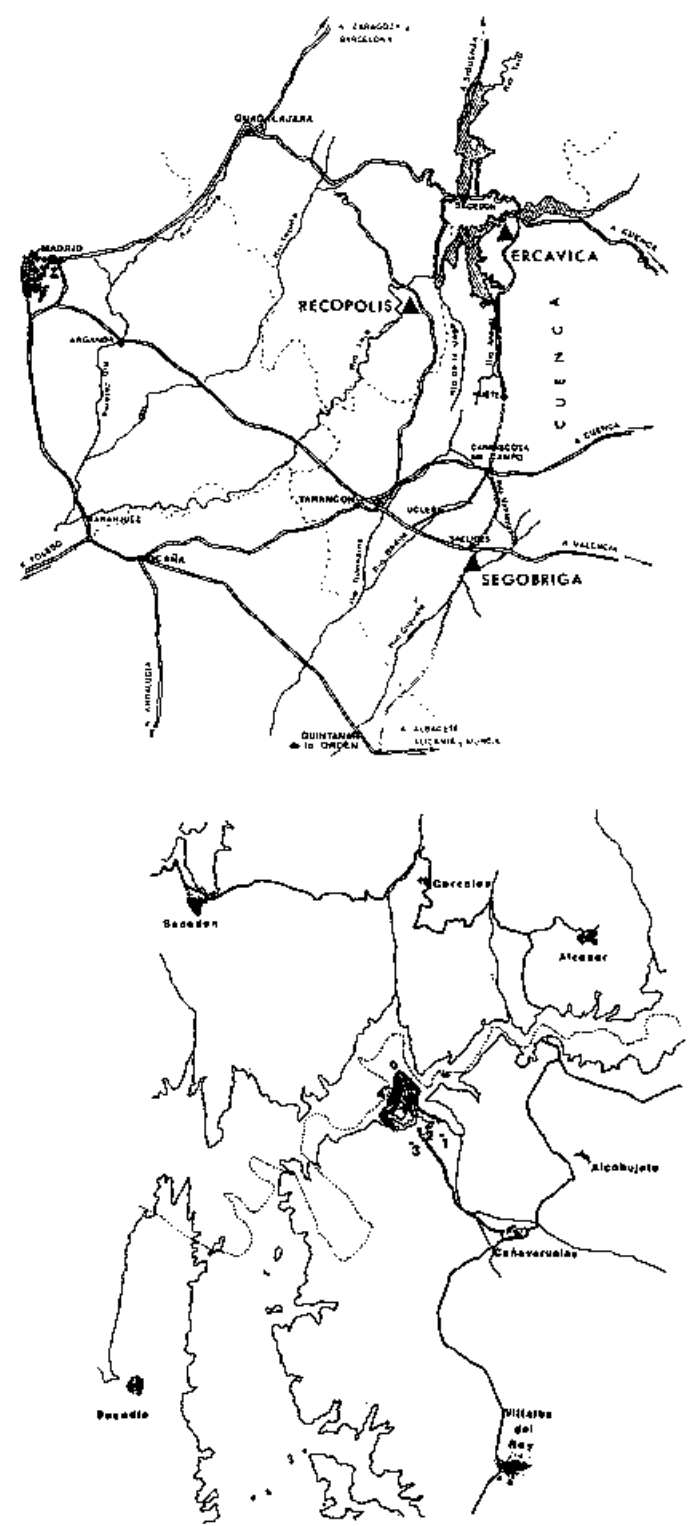

Fig. 1. A. Situación de la ciudad romano-Visigoda de Arćivica (Cañaveruelas, Cuenca). B. Płano de ubicación de los restos arqueológicos de época visigoda en la ciudad de Arcávica: Monasterio (1), "eremitorio" (2), El Pocillo (4) y necrópolis de La Rinconada (4).

De Hispania Visigoda Hispania Sacra 48 (1996) 

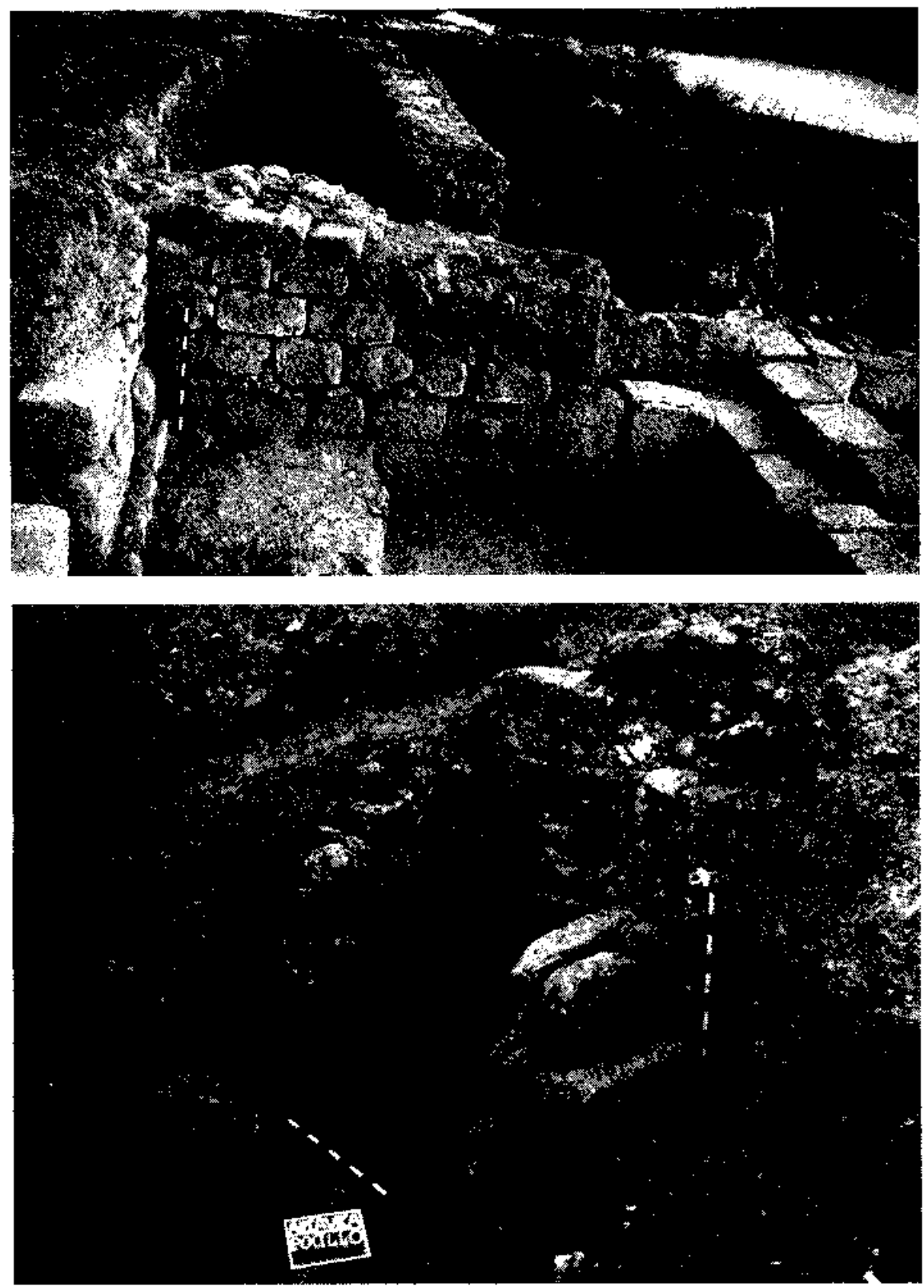

Fig. 2 A. Aré́vica. Monasterio. Vista de la cilla. B. El Pocillo. Vista general desde el Este.

De Hispania Visigoda

Hispania Sacra 48 (1996) 


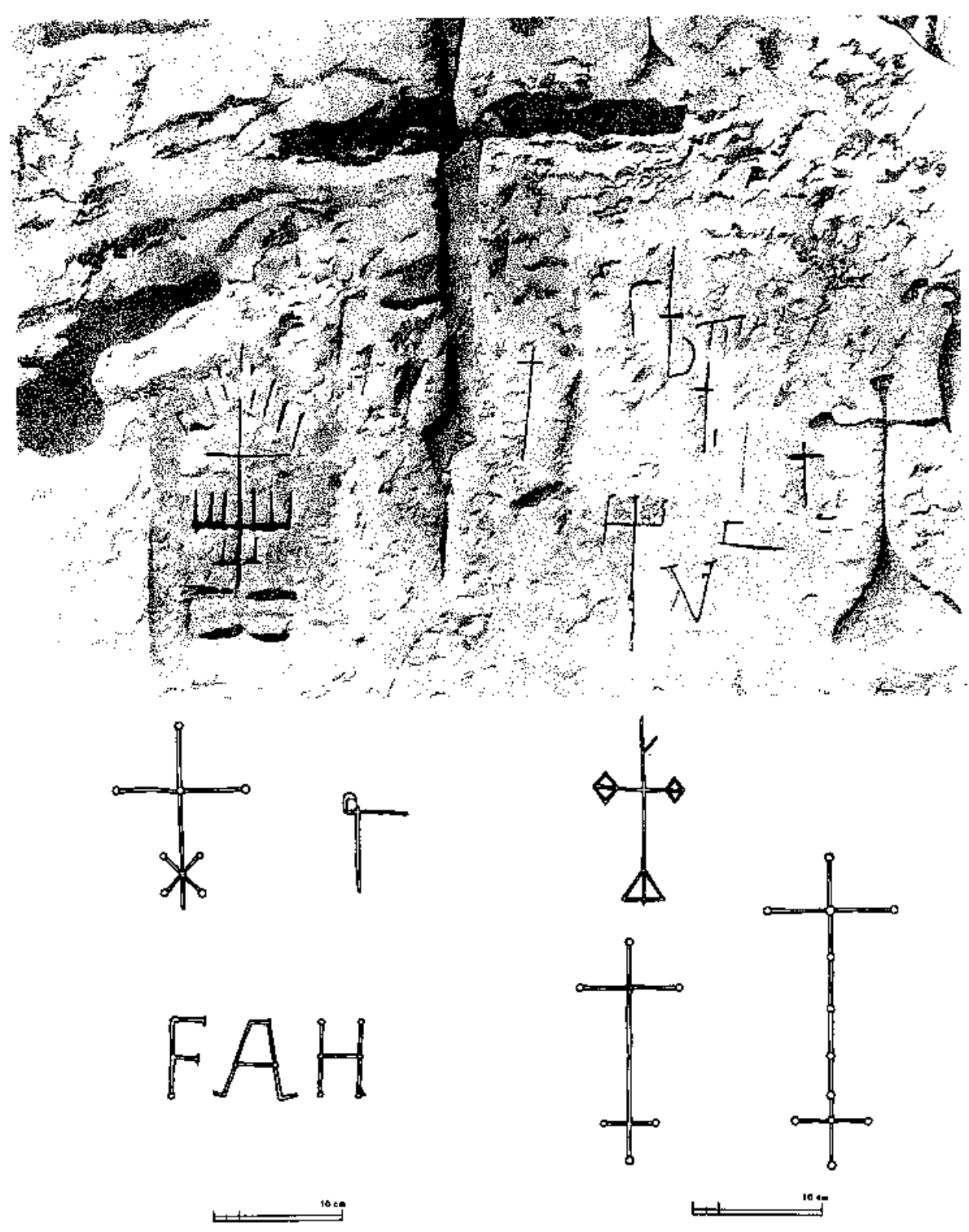

Fig. 3. A. Arcávica. Grabados del exterior del "eremitorio": Cruz y candelabro de siete brazos, gran cruz central, cruz de calvario y signos advocatorios. B. Grabados del interior del "eremitorio". Panel central y oriental: Cruz sobre aspas e inscripciones sobre la tumba de Donato. C. Grabados del interior del "eremitorio". Panel Occidental: Cruz monográftca y cruces

De Hispania Visigoda Hisparia Sacra 48 (1996) 


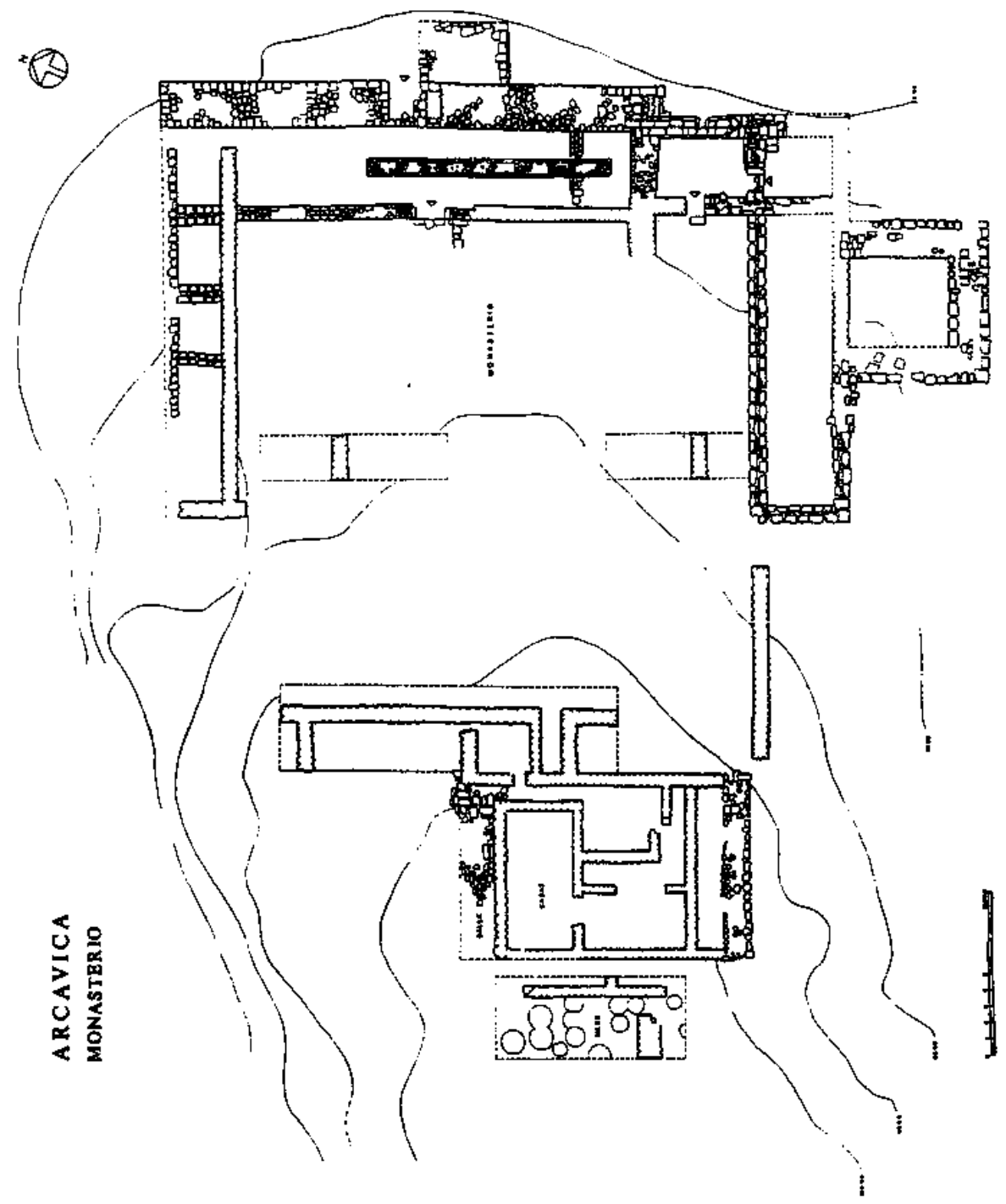

Arcávica (Cañarselas, Cuenca). Plano del Monasterio.

De Hispania Visigoda

Hispania Sacra 48 (1996) 


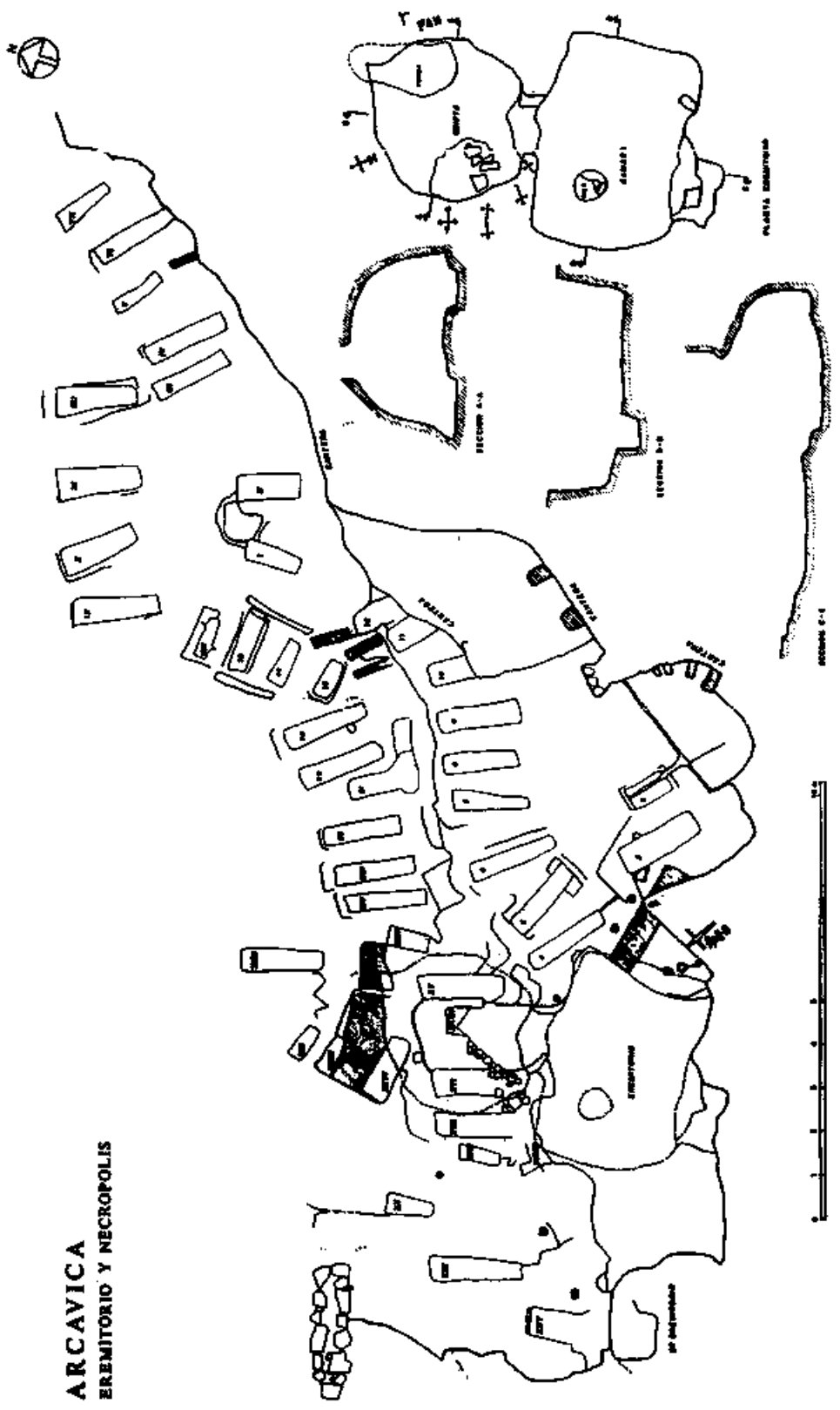

Arcávica. "Eremitorio" y necrópolis. Plano y secciones.

De Hispania Visigoda Hispania Sacra 48 (1996) 


\section{A R CAVICA \\ POCILLO}

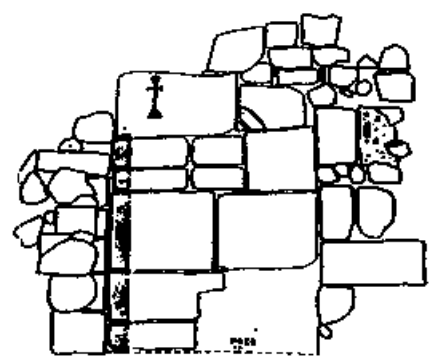

ALZADO
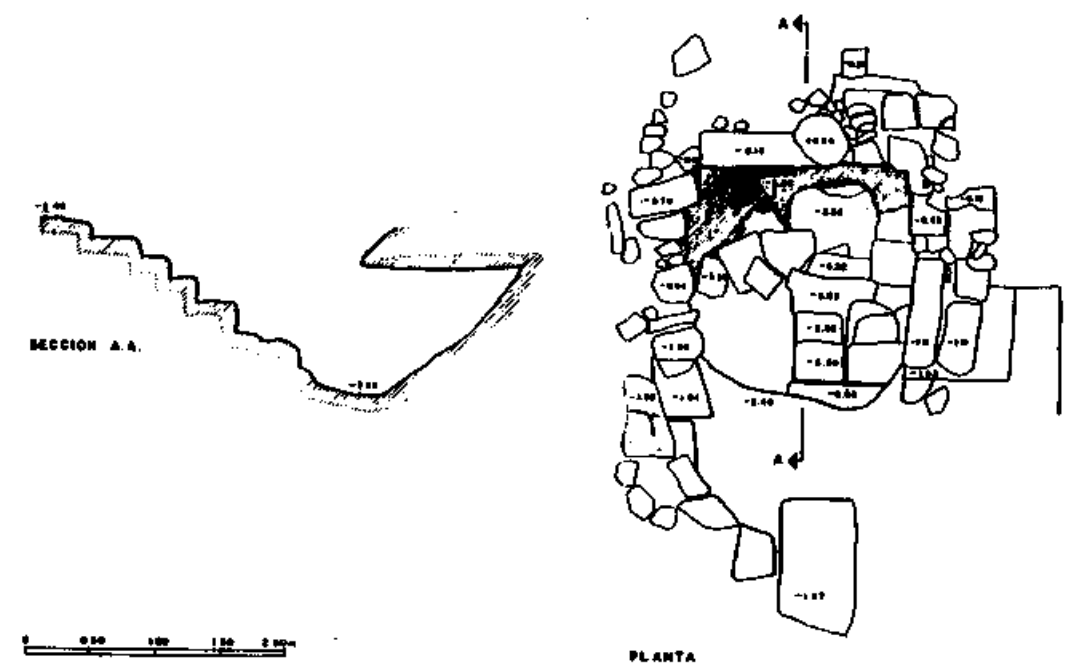

年

Arcávica, El Pocillo. Planta, alzado y sección.

De Hispania Visigoda

Hispania Sacra 48 (1996) 